\title{
Limited impact on decadal-scale climate change from increased use of natural gas
}

\author{
Haewon McJeon ${ }^{1}$, Jae Edmonds ${ }^{1}$, Nico Bauer ${ }^{2}$, Leon Clarke ${ }^{1}$, Brian Fisher ${ }^{3}$, Brian P. Flannery ${ }^{4}$, Jérôme Hilaire ${ }^{2}$, Volker Krey ${ }^{5}$, \\ Giacomo Marangoni ${ }^{6}$, Raymond $\mathrm{Mi}^{3}$, Keywan Riahi ${ }^{5}$, Holger Rogner ${ }^{5}$ \& Massimo Tavoni ${ }^{6}$
}

The most important energy development of the past decade has been the wide deployment of hydraulic fracturing technologies that enable the production of previously uneconomic shale gas resources in North America $^{1}$. If these advanced gas production technologies were to be deployed globally, the energy market could see a large influx of economically competitive unconventional gas resources ${ }^{2}$. The climate implications of such abundant natural gas have been hotly debated. Some researchers have observed that abundant natural gas substituting for coal could reduce carbon dioxide $\left(\mathrm{CO}_{2}\right)$ emissions $^{3-6}$. Others have reported that the non- $\mathrm{CO}_{2}$ greenhouse gas emissions associated with shale gas production make its lifecycle emissions higher than those of coall $^{7,8}$. Assessment of the full impact of abundant gas on climate change requires an integrated approach to the global energyeconomy-climate systems, but the literature has been limited in either its geographic scope $\mathrm{e}^{9,10}$ or its coverage of greenhouse gases ${ }^{2}$. Here we show that market-driven increases in global supplies of unconventional natural gas do not discernibly reduce the trajectory of greenhouse gas emissions or climate forcing. Our results, based on simulations from five state-of-the-art integrated assessment models ${ }^{11}$ of energyeconomy-climate systems independently forced by an abundant gas scenario, project large additional natural gas consumption of up to +170 per cent by 2050 . The impact on $\mathrm{CO}_{2}$ emissions, however, is found to be much smaller (from -2 per cent to +11 per cent), and a majority of the models reported a small increase in climate forcing (from -0.3 per cent to +7 per cent) associated with the increased use of abundant gas. Our results show that although market penetration of globally abundant gas may substantially change the future energy system, it is not necessarily an effective substitute for climate change mitigation policy ${ }^{9,10}$.

Five research teams projected the evolution of the future global energy system up to 2050 under two alternative assumptions about natural gas supply: 'Conventional Gas' and 'Abundant Gas' (Fig. 1 and Methods). Each natural gas supply curve was constructed based on the synthesis of natural gas supply and geographic distribution in the Global Energy Assessment (GEA) report ${ }^{12}$.

The Conventional Gas scenario assumes the maximum recoverable resources to be 11,000 exajoules (EJ) in 2010, a total consistent with conventional resources that have extraction costs below $\$ 3$ per gigajoule (GJ). (One EJ equals one quintillion $\left(10^{18}\right)$ joules and one GJ equals one billion $\left(10^{9}\right)$ joules.) This supply curve reflects an estimate of economically recoverable gas consistent with technology available before the shale gas revolution.

The Abundant Gas scenario is characterized by both the global abundance of natural gas resources and substantially reduced extraction costs. This scenario envisions that advanced natural gas extraction technologies become globally applicable beyond North America, allowing extraction of previously uneconomic unconventional resources. To represent this scenario, we assumed that technological change halves the extraction cost in GEA between 2010 and 2050, allowing more than 30,000 EJ of cumulative natural gas to be produced at or below $\$ 3$ per GJ, with additional resources producible at higher prices. This rate of cost reduction is on the higher end compared to other studies ${ }^{2,9,10}$. This scenario is designed to provide a potential upper bound on global gas supply and should not be interpreted as the most likely case (see Methods for a broader range of supply assumptions). Furthermore, this rate of cost reduction is more aggressive than that of most low-carbon energy sources against which natural gas is competing (see Extended Data Table 1 for variance across the models).

For both scenarios, we did not simulate future climate policies beyond those already in effect. The two scenarios therefore explore the degree to which market penetration of abundant gas alone can mitigate greenhouse gas emissions (see Methods).

Five integrated assessment models (IAMs) are employed in this study: BAEGEM $^{13}$, GCAM $^{14}$, MESSAGE $^{15}$, REMIND $^{16}$ and WITCH ${ }^{17}$. These IAMs belong to a class of models designed to assess the implications of changes in the global energy system on climate forcing. They have been used extensively to project emission scenarios for global and regional assessments. For example, GCAM and MESSAGE provided two of the four Representative Concentration Pathways (RCPs) used in the Intergovernmental Panel on Climate Change's Fifth Assessment Report ${ }^{18,19}$.

The models integrate energy, economy, and climate systems to assess their interaction in a consistent framework. All models feature explicit representation of energy markets with price-responsive demand and supply for coal, oil, and gas, as well as for low-carbon energy sources ${ }^{20}$. The capability to simulate the effects of price changes on the scale and the composition of the future energy system is crucial for this study,

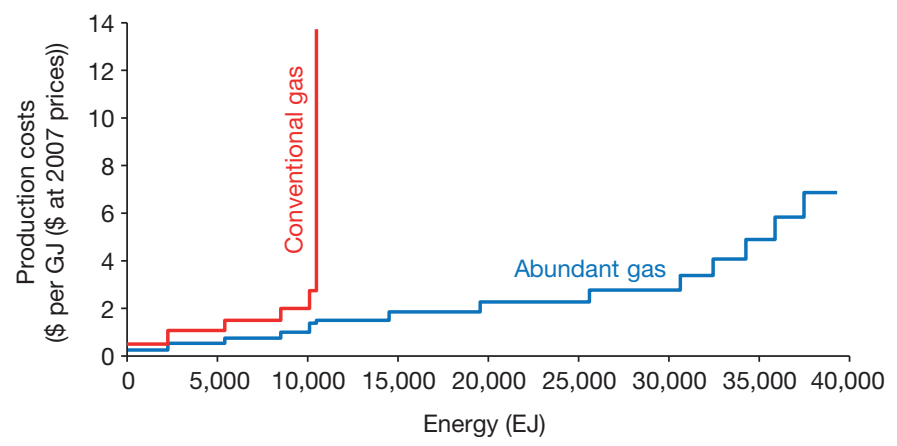

Figure 1 Global natural gas supply curves in 2050. The current natural gas supply curves provided by Global Energy Assessment ${ }^{12}$. Future cost reduction assumptions are documented in the Methods. These supply costs are not the actual prices in the market place. The costs do not include taxes or royalties, nor do they include external environmental or social costs associated with gas production $^{12}$. $\$ 3$ per GJ is equivalent to $\$ 3.2$ per $\mathrm{mmBtu}$. (One $\mathrm{mmBtu}$ is one million British thermal units.) US dollars at 2007 constant prices.

${ }^{1}$ Pacific Northwest National Laboratory, JGCRI, 5825 University Research Court, Suite 3500, College Park, Maryland 20740, USA. ${ }^{2}$ Potsdam Institute for Climate Impact Research, PO Box 6012 03, D-14412 Potsdam, Germany. ${ }^{3}$ BAEconomics, PO Box 5447, Kingston, Australian Capital Territory 2604, Australia. ${ }^{4}$ Resources for the Future, 1616 P Street Northwest, Washington, DC 20036 , USA.

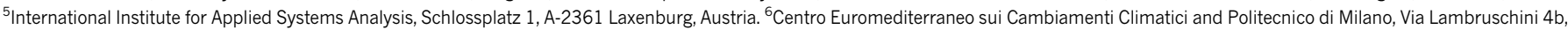
20156 Milan, Italy. 
because these effects determine the changes in emissions and corresponding changes in climate forcing.

The models are harmonized to share common natural gas supply curve assumptions, but otherwise differ widely in model architecture, geospatial resolution, socioeconomic assumptions, and technology projections (see Table 1 and Methods for a detailed description of the model differences and similarities). To the extent that a similar result is produced by this diverse set of models, we are more confident that the result is not simply an idiosyncratic artefact of an individual modelling method, but rather is reflective of more fundamental forces.

The models independently projected the future energy system for the two natural gas supply scenarios. All five models reported that the abundant gas supply leads to additional gas consumption, as well as additional gas-fired electricity consumption, compared to the Conventional Gas scenario. However, the speed of divergence and the size of the difference in gas consumption varied across models: from $11 \%$ in WITCH to $170 \%$ in REMIND in 2050 (Fig. 2a). The models agreed on the pattern of sector penetration. Power production showed the largest shift towards gas substituting for all other fuels, most prominently coal. Smaller shifts occurred in industry and buildings (Fig. 3a). The models also agreed that natural gas continues to have a minor role only in transportation.

Despite major changes to the global energy system and the substantial increase in natural gas consumption, the models agreed that additional supply of natural gas in the energy market does not discernibly reduce fossil fuel $\mathrm{CO}_{2}$ emissions. Future $\mathrm{CO}_{2}$ emissions are similar in magnitude with and without abundant gas, as the two emission trajectories continue to rise over time at similar rates (Fig. 2b). For GCAM, MESSAGE, and WITCH, the $\mathrm{CO}_{2}$ emissions for both scenarios were within $2 \%$ of each other in 2050. The BAEGEM (11\%) and REMIND (5\%) models showed larger differences, but emissions increased-rather than decreased-under the Abundant Gas scenario.

The results demonstrate that abundant gas will not necessarily reduce $\mathrm{CO}_{2}$ emissions. There are two forces at work: substitution and scale effect. First, additional natural gas consumption largely substitutes for coal, but not exclusively. All five models found that gas substitutes for all other primary fuels - such as nuclear and renewables-although coal loses the largest market share in all models (Fig. 3a). In 2050, abundant gas on average substitutes for $18 \%$ of coal and $17 \%$ of low-carbon energy ( $10 \%$ and $8 \%$ respectively for the $2010-2050$ cumulative total). Hence, the effect of natural gas on $\mathrm{CO}_{2}$ emissions is not based on the difference between the emission factors of gas and of coal, but on the emission factor of gas relative to that of a broader basket of energy sources. The natural gas emission factor ( $56 \mathrm{~kg}$ of $\mathrm{CO}_{2}$ per $\mathrm{GJ}$ ) is about half of the coal emission factor $\left(96 \mathrm{~kg} \text { of } \mathrm{CO}_{2} \text { per GJ) }\right)^{21}$. However, it is not substantially lower than the average global $\mathrm{CO}_{2}$ emissions per unit of energy: $68 \mathrm{~kg}$ of $\mathrm{CO}_{2}$ per $\mathrm{GJ}$ (2050 model average). Consequently, even if natural gas were to substitute for the entire global energy supply, $\mathrm{CO}_{2}$ emissions would decline by a maximum of $20 \%$. Considering the model average of a $36 \%$ share for natural gas in the global energy system in 2050 , the actual emission reduction effect would be a fraction of the maximum.

Second, lower natural gas prices accelerate economic activity, reduce the incentive to invest in energy-saving technologies, and lead to an aggregate expansion of the total energy system: a scale effect. All models reported greater total global primary energy consumption ( $6 \%$ on average) in the Abundant Gas scenario compared with the Conventional Gas scenario. All else being equal, increased energy use leads to increased $\mathrm{CO}_{2}$ emissions. All models reported that the combined effect of the two forces-substitution and scale effect-does not result in a discernible reduction in emissions and, in some cases, leads to increased $\mathrm{CO}_{2}$ emissions.

The emissions data from the models were processed through a simple climate model, MAGICC6 (Model for the Assessment of GreenhouseGas Induced Climate Change), to assess the combined effects of all greenhouse gases and climate forcing agents (see Methods) ${ }^{22}$. The results echoed those that were observed for $\mathrm{CO}_{2}$ emissions: climate forcing and associated temperature change are not discernibly reduced under the Abundant Gas scenario (Fig. 2c, d and Fig. 3b, c). Four models that endogenously model fugitive methane emissions reported increased climate forcing with abundant gas. This is largely driven by increased forcing from fugitive methane emissions associated with increases in gas consumption. The WITCH model, with exogenously specified methane emissions, reported virtually no change in forcing $(-0.3 \%)$.

Furthermore, four models reported the net change in forcing to be less than 3\%. REMIND reported radiative forcing increase of $7 \%$; more than half of that increase came from reductions in coal use and associated aerosol emissions (reduced cooling). Two other models that also simulate aerosol emissions endogenously (GCAM and MESSAGE), also reported a reduced cooling effect from aerosols, but at a smaller scale.

The core finding of this research is that increases in unconventional gas supply in the energy market could substantially change the global energy system over the decades ahead without producing commensurate

Table 1 | Overview of the five modelling systems

\begin{tabular}{|c|c|c|c|c|c|}
\hline Model & BAEGEM & GCAM & MESSAGE & REMIND & WITCH \\
\hline Full name & $\begin{array}{l}\text { BAEconomics General } \\
\text { Equilibrium Model }\end{array}$ & $\begin{array}{l}\text { Global Change } \\
\text { Assessment Model }\end{array}$ & $\begin{array}{l}\text { Model for Energy Supply } \\
\text { Systems And their } \\
\text { General Environmental } \\
\text { impact }\end{array}$ & $\begin{array}{l}\text { Regional Model of } \\
\text { Investments and } \\
\text { Development }\end{array}$ & $\begin{array}{l}\text { World Induced Technical } \\
\text { Change Hybrid }\end{array}$ \\
\hline Institutional steward & BAEconomics & $\begin{array}{l}\text { Pacific Northwest } \\
\text { National Laboratory } \\
\text { (PNNL) }\end{array}$ & $\begin{array}{l}\text { International Institute } \\
\text { for Applied Systems } \\
\text { Analysis (IIASA) }\end{array}$ & $\begin{array}{l}\text { Potsdam Institute for } \\
\text { Climate Impact } \\
\text { Research (PIK) }\end{array}$ & $\begin{array}{l}\text { Centro Euromediterraneo } \\
\text { sui Cambiamenti Climatici } \\
\text { (CMCC) }\end{array}$ \\
\hline Location & Kingston, Australia & $\begin{array}{l}\text { College Park, } \\
\text { Maryland, USA }\end{array}$ & Laxenburg, Austria & Potsdam, Germany & Milan, Italy \\
\hline Brief description & $\begin{array}{l}\text { BAEGEM is a global } \\
\text { dynamic-recursive, } \\
\text { multi-region, multi-sector, } \\
\text { computable general } \\
\text { equilibrium model; it } \\
\text { includes energy use, } \\
\text { transformation and } \\
\text { technology detail }\end{array}$ & $\begin{array}{l}\text { GCAM is a long-term, } \\
\text { global, dynamic-recursive, } \\
\text { integrated assessment } \\
\text { model of human and } \\
\text { physical Earth systems, } \\
\text { including } 14 \text { geopolitical } \\
\text { and } 151 \text { land-use } \\
\text { regions; it includes } \\
\text { detailed technological } \\
\text { representations for } \\
\text { energy, land use, and } \\
\text { the economy }\end{array}$ & $\begin{array}{l}\text { MESSAGE is an } \\
\text { integrated assessment } \\
\text { modelling framework, } \\
\text { combining a global } \\
\text { (multi-region, multi- } \\
\text { sector) systems } \\
\text { engineering, } \\
\text { inter-temporal } \\
\text { optimization model, } \\
\text { an aggregated macro- } \\
\text { economic model, and a } \\
\text { simple climate model }\end{array}$ & $\begin{array}{l}\text { REMIND is a multi- } \\
\text { regional, general } \\
\text { equilibrium model of } \\
\text { the global economy, } \\
\text { energy, and climate } \\
\text { systems; it includes } \\
\text { energy supply, } \\
\text { transformation } \\
\text { technologies and } \\
\text { demand details; } \\
\text { intertemporal } \\
\text { optimization methods } \\
\text { solve for the equilibrium }\end{array}$ & $\begin{array}{l}\text { WITCH is a multi-region, } \\
\text { long-term, dynamic } \\
\text { optimization, economy- } \\
\text { energy-climate model, } \\
\text { characterized by } \\
\text { endogenous technological } \\
\text { change and a game } \\
\text { theoretic set-up with } \\
\text { strategic interaction } \\
\text { among regions }\end{array}$ \\
\hline $\begin{array}{l}\text { Climate model used } \\
\text { for this study }\end{array}$ & $\begin{array}{l}\text { MAGICC } 6.0 \\
\text { (natively integrated with } \\
\text { MAGICC 5.3) }\end{array}$ & $\begin{array}{l}\text { MAGICC } 6.0 \\
\text { (natively integrated } \\
\text { with MAGICC 5.3) }\end{array}$ & $\begin{array}{l}\text { MAGICC } 6.0 \\
\text { (natively integrated } \\
\text { with MAGICC 5.3) }\end{array}$ & MAGICC 6.0 & MAGICC 6.0 \\
\hline Detailed description & Ref. 13 & Ref. 14 & Ref. 15 & Ref. 16 & Ref. 17 \\
\hline
\end{tabular}


BAEGEM

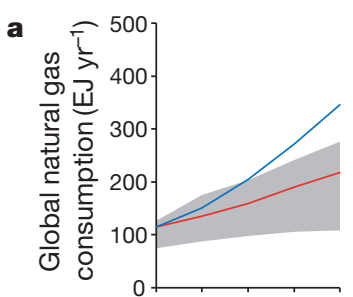

b

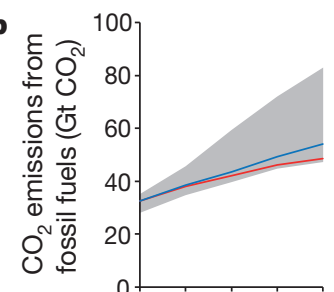

c

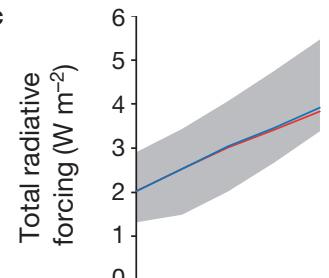

d

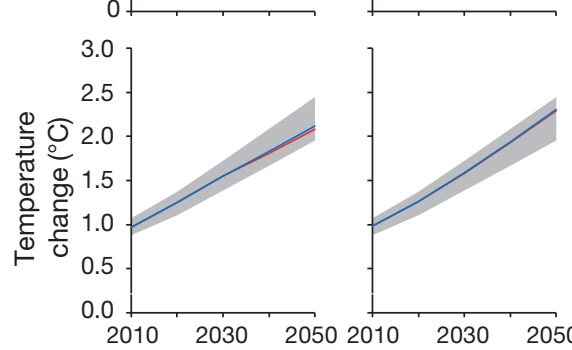

Literature range
MESSAGE
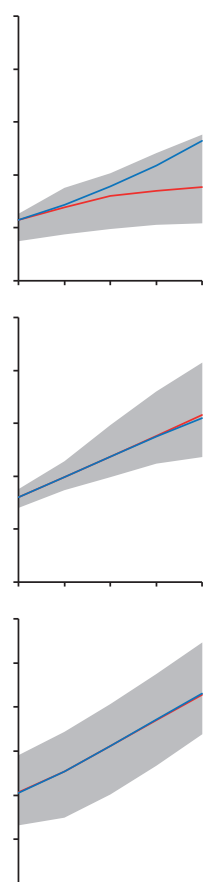

$20502030 \quad 2050$
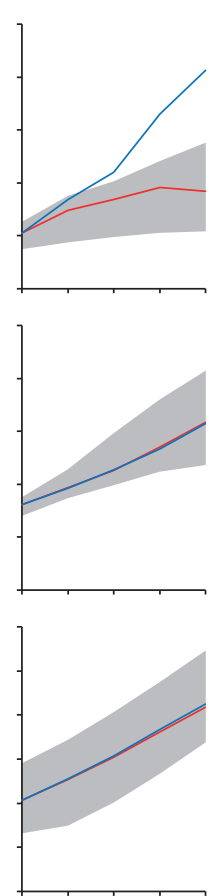

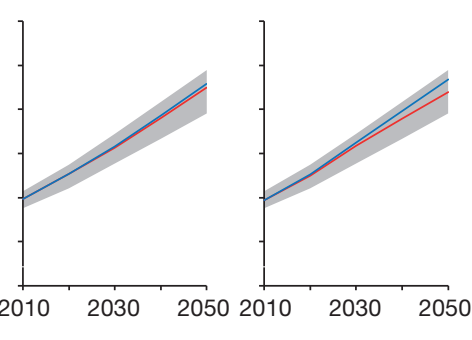

- Conventional gas
REMIND

WITCH
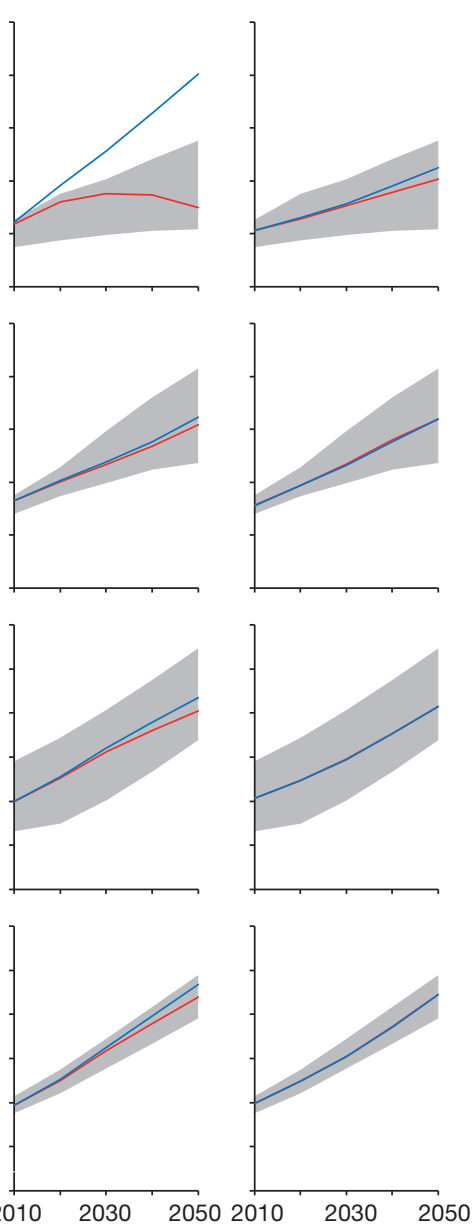

a
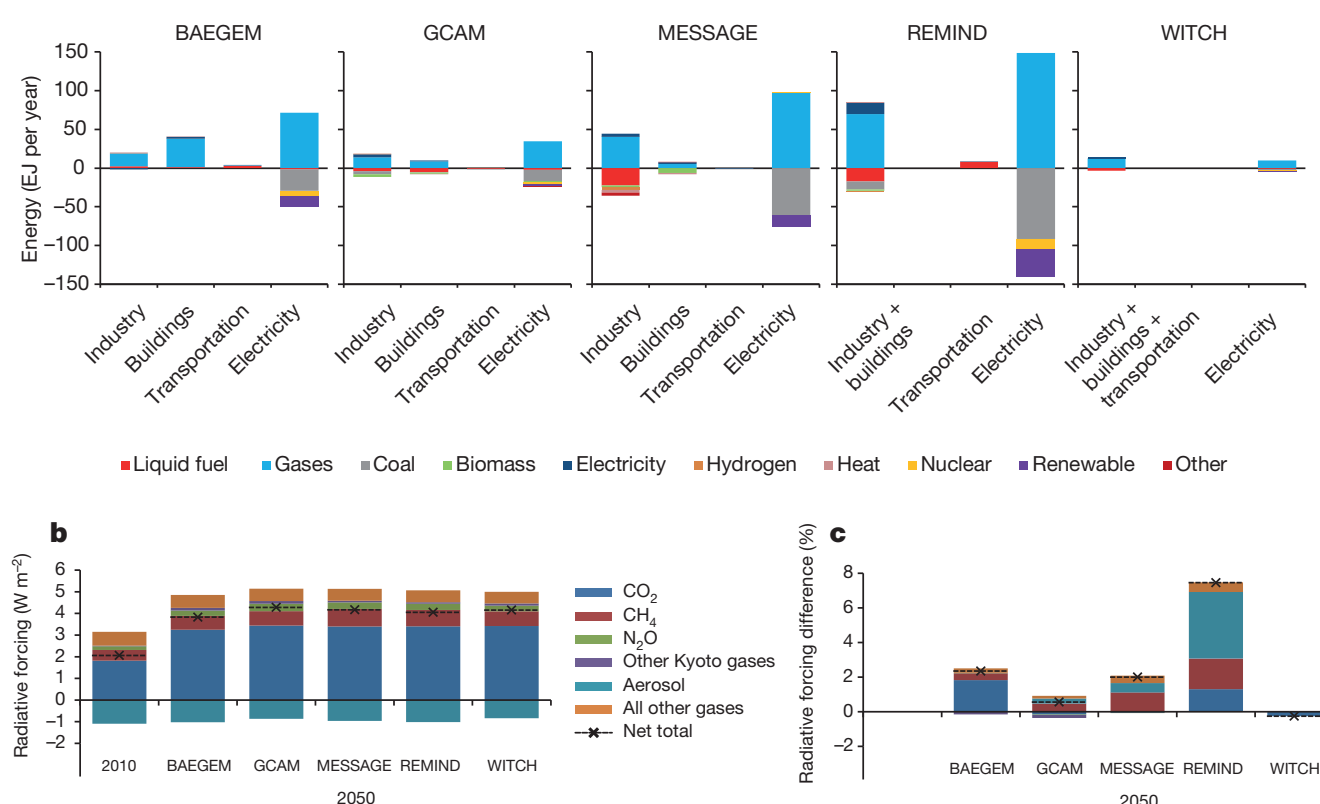

2050

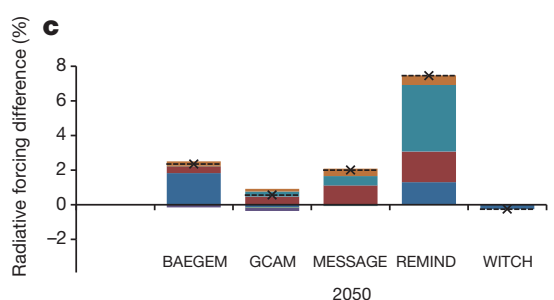

Figure $2 \mid$ Comparison of the model results 2010-2050. a, Global natural gas consumption. The relatively small difference in gas production in WITCH (11\%) becomes considerably greater in the second half of the century, beyond the time scope of this study. $\mathbf{b}, \mathrm{CO}_{2}$ emissions from fossil fuels. c, Total radiative forcing. d, Global mean surface temperature change (from pre-industrial average 1750-1849). The literature range is obtained from refs 29 and 30.
Figure 3 | Global energy consumption and radiative forcing in 2050. a, Differences in energy use by sector and fuel (the Abundant Gas scenario minus the Conventional Gas scenario) in 2050. One avenue for possible change in the transportation sector is through the use of gas in transportation fuel production. The MESSAGE model reports this effect at a noticeable scale (10\%). b, Year 2010 and year 2050 composition of radiative forcing for the Conventional Gas scenario for five models. c, Year 2050 relative difference in radiative forcing (the Abundant Gas scenario minus the Conventional Gas scenario) for the five models. $1 \%$ difference in forcing for model average is equivalent to $0.042 \mathrm{~W} \mathrm{~m}^{-2}$. 
changes in emissions or climate forcing. The result stems from three effects: abundant gas substituting for all energy sources; lower energy prices increasing the scale of the energy system; and changes in non$\mathrm{CO}_{2}$ emissions. This result is potentially sensitive to a range of model assumptions.

One important assumption is that market forces are allowed to work themselves out largely unfettered. Our results would be different if policies that limit natural gas's ability to substitute for low-carbon energy were implemented on a global scale. To explore this sensitivity we recalculated the emissions assuming that abundant gas substitutes exclusively for coal. This assumption is analogous to a global clean energy standard where the capacities of carbon-free energy sources are exogenously specified. With the exception of BAEGEM, the models reported $\mathrm{CO}_{2}$ emission reductions between $-0.1 \%$ and $-6 \%$ (Extended Data Table 2 ). BAEGEM's result of a 7\% increase was driven by an overall energy expansion of $11 \%$.

The results are also influenced by assumptions about technological change in other domains. Although the results reported here assumed changes to gas supply technology alone, oil production is experiencing similar technological advances. Extending the analysis to oil as well as gas production would not be expected to lower future $\mathrm{CO}_{2}$ emissions or climate forcing because the carbon-to-energy ratio for oil is approximately $35 \%$ higher than that of natural gas.

Fugitive methane emissions associated with natural gas production, transmission, and distribution is another important factor. On the one hand, conventional estimates for natural gas methane leakage rates have been less than $2 \%$ of production ${ }^{23,24}$, and studies have shown that the leakage rate is not considerably different between conventional and unconventional sources ${ }^{25,26}$. On the other hand, other studies have reported substantially higher leakage rates ${ }^{7,27,28}$. To test the sensitivity of our results to these assumptions, we chose the highest value (7.9\%; ref. 7) from a range of methane leakage rates found in the literature. We then recalculated climate forcing and found that the effect of abundant gas is to increase climate forcing by $0.2 \%$ to $12 \%$ in 2050 , which is $0.5 \%$ to $5 \%$ higher than in our central scenario (Extended Data Fig. 1). In other words, the finding that abundant gas does not discernibly reduce climate forcing is consistently reported over a wide range of fugitive methane rates found in the literature. Furthermore, under high fugitive emission assumption, three models reported increased climate forcing of more than $5 \%$.

This analysis focused solely on the potential of abundant gas to affect greenhouse gas emissions in the absence of greenhouse gas mitigation policies beyond those already in effect. The interaction between abundant natural gas and greenhouse gas mitigations policies is another issue in need of further examination ${ }^{9,10}$. Finally, we note that the global deployment of improved natural gas extraction technology carries implications not only for climate change, but also for many other important concerns including air and water quality, energy security, access to modern energy, and economic growth ${ }^{1,2,8}$.

Online Content Methods, along with any additional Extended Data display items and Source Data, are available in the online version of the paper; references unique to these sections appear only in the online paper.

\section{Received 25 April; accepted 2 September 2014.}

Published online 15 October 2014.

1. Sovacool, B. K. Cornucopia or curse? Reviewing the costs and benefits of shale gas hydraulic fracturing (fracking). Renew. Sustain. Energy Rev. 37, 249-264 (2014).

2. International Energy Agency. Are We Entering a Golden Age of Gas? (IEA Report, 2011)

3. Hultman, N., Rebois, D., Scholten, M. \& Ramig, C. The greenhouse impact of unconventional gas for electricity generation. Environ. Res. Lett. 6, 044008 (2011).

4. Moniz, E. J. et al. The Future of Natural Gas: An Interdisciplinary MIT Study (MIT, 2011); http://mitei.mit.edu/system/files/NaturalGas_Report.pdf.

5. Brown, S. Krupnick, A. \& Walls, M. Natural Gas: a Bridge to a Low-Carbon Future (Resource for the Future, 2009); http://www.rff.org/RFF/Documents/RFF-IB-0911.pdf.

6. Levi, M. Climate consequences of natural gas as a bridge fuel. Clim. Change $\mathbf{1 1 8}$, 609-623 (2013).
7. Howarth, R. W., Santoro, R. \& Ingraffea, A. Methane and the greenhouse-gas footprint of natural gas from shale formations. Clim. Change 106, 679-690 (2011)

8. Howarth, R. W., Ingraffea, A. \& Engelder, T. Natural gas: should fracking stop? Nature 477, 271-275 (2011).

9. Newell, R. G. \& Raimi, D. Implications of shale gas development for climate change. Environ. Sci. Technol. 48, 8360-8368 (2014).

10. Energy Modeling Forum. Changing the game? Emissions and Market Implications of New Natural Gas Supplies EMF Report 26 (EMF, 2013); https://web.stanford.edu/ group/emf-research/docs/emf26/Summary26.pdf.

11. Edmonds, J. A. et al. in Climate Change Modeling Methodology 169-209 (Springer, 2012).

12. Rogner, H. et al. in Global Energy Assessment 423-512 (Cambridge Univ. Press, 2012).

13. Mi, R. \& Fisher, B. S. BAEGEM Model Documentation (BAEconomics, 2014); http://www.baeconomics.com.au/wp-content/uploads/2014/02/BAEGEMdocumentation-21Feb14.pdf.

14. Calvin, K. et al. GCAM Wiki Documentation (Pacific Northwest National Laboratory, 2011); http://wiki.umd.edu/gcam/.

15. Riahi, K., Grübler, A. \& Nakicenovic, N. Scenarios of long-term socio-economic and environmental development under climate stabilization. Technol. Forecast. Soc Change 74, 887-935 (2007).

16. Bauer, N. et al. Global fossil energy markets and climate change mitigation-an analysis with REMIND. Clim. Change (in the press).

17. Bosetti, V., Carraro, C., Galeotti, M., Massetti, E. \& Tavoni, M. A world induced technical change hybrid model. Energy J. 27, 13-37 (2006).

18. Van Vuuren, D. P. et al. The representative concentration pathways: an overview. Clim. Change 109, 5-31 (2011).

19. Intergovernmental Panel on Climate Change. Climate Change 2013: The Physical Science Basis. Contribution of Working Group I to the Fifth Assessment Report of the Intergovernmental Panel on Climate Change (eds Stocker, T. F. et al.) (Cambridge Univ. Press, 2013)

20. Bauer, N. et al. $\mathrm{CO}_{2}$ emission mitigation and fossil fuel markets: dynamic and international aspects of climate policies. Technol. Forecast. Soc. Change (in the press).

21. Intergovernmental Panel on Climate Change IPCC Guidelines for National Greenhouse Gas Inventories (IPCC report, 2006); http://www.ipcc-nggip.iges.or.jp/ public/2006gl/.

22. Meinshausen, M. Raper, S. C. B.\& Wigley, T. M. L.Emulating coupled atmosphereocean and carbon cycle models with a simpler model, MAGICC6: Part I-model description and calibration. Atmos. Chem. Phys. 11, 1417-1456 (2011).

23. Environmental Protection Agency Inventory of Greenhouse Gas Emissions and Sinks 1990-2009 (EPA Publication 430-R-11-005, 2011); http://www.epa.gov/ climatechange/Downloads/ghgemissions/US-GHG-Inventory-2011-Complete_ Report.pdf.

24. Venkatesh, A., Jaramillo, P., Griffin, W. M. \& Matthews, H. S. Uncertainty in life cycle greenhouse gas emissions from United States natural gas end-uses and its effects on policy. Environ. Sci. Technol. 45, 8182-8189 (2011)

25. Burnham, A. et al. Life-cycle greenhouse gas emissions of shale gas, natural gas, coal, and petroleum. Environ. Sci. Technol. 46, 619-627 (2012).

26. Laurenzi, I. J. \& Jersey, G. R. Life cycle greenhouse gas emissions and freshwater consumption of Marcellus shale gas. Environ. Sci. Technol. 47, 4896-4903 (2013).

27. Miller, S. M. et al. Anthropogenic emissions of methane in the United States. Proc. Natl Acad. Sci. USA 110, 20018-20022 (2013).

28. Brandt, A. et al. Methane leaks from North American natural gas systems. Science 343, 733-735 (2014)

29. Kriegler, E. et al. The role of technology for achieving climate policy objectives: overview of the EMF 27 study on global technology and climate policy strategies. Clim. Change 123, 353-367 (2014).

30. Calvin, K. et al. The role of Asia in mitigating climate change: results from the Asia modeling exercise. Energy Econ. 34, S251-S260 (2012).

Supplementary Information is available in the online version of the paper.

Acknowledgements B.F. and R.M. and their development of BAEGEM were supported by BAEconomics with assistance for special applications to the resource sector from Rio Tinto (Australia). H.M., L.C., J.E. and B.P.F. were supported by the Global Technology Strategy Project. V.K., K.R. and H.R. were supported by the International Institute for Applied Systems Analysis cross-cutting project on unconventional natural gas. N.B. and $J . H$. were supported by funding from the German Federal Ministry of Education and Research in the project 'Economics of Climate Change'. G.M. and M.T. were supported by the Italian Ministry of Education, University and Research and the Italian Ministry of Environment, Land and Sea under the GEMINA project. We thank M. Jeong and E. Golman for research assistance. The views and opinions expressed in this paper are those of the authors alone.

Author Contributions H.M., J.E., L.C. and B.P.F. proposed the research design. H.R. provided the resource supply curves. H.M. and J.E. provided GCAM data and wrote the first draft of the paper. N.B. and J.H. provided REMIND data. B.F. and R.M. provided BAEGEM data. V.K. and K.R. provided MESSAGE data. G.M. and M.T. provided WITCH data. All authors contributed to writing the paper.

Author Information Reprints and permissions information is available at www.nature.com/reprints. The authors declare no competing financial interests. Readers are welcome to comment on the online version of the paper. Correspondence and requests for materials should be addressed to H.M. (haewon.mcjeon@pnnl.gov). 


\section{METHODS}

Gas supply curves. Natural gas supply curves are harmonized across all the models. The Conventional Gas scenario represents an estimate of economically recoverable gas consistent with technology available before the shale gas revolution. This natural gas supply curve is constructed based on the synthesis of natural gas supply and geographic distribution in the GEA report ${ }^{12}$. GEA's 2010 natural gas supply curve is truncated at 11,000 EJ of cumulative global supply to represent limited conventional gas supply. No future cost reduction from technological change is assumed. This curve represents a lower bound of global natural gas supply (see green curve in Extended Data Fig. 2)

The Abundant Gas scenario represents an upper bound of global natural gas supply. This supply curve is characterized by both the global abundance of the resources and the substantially lower extraction costs. Global abundance is implemented by allowing both conventional and unconventional gas in GEA estimates ${ }^{12}$ to be fully available for extraction. A cumulative supply of 39,000 EJ is assumed to be available globally.

Lower extraction cost is implemented by future technological changes reducing extraction cost over time. The extraction costs of early adopters (USA and Canada) are assumed to reduce exponentially by $1.7 \%$ per year over the course of 2011-2050. Extraction costs from all other regions are assumed to reduce exponentially by $2.0 \%$ per year over the course of 2016-2050. In all regions, the cost of extraction is reduced to half by 2050 from the GEA's 2010 estimate.

This is on the aggressive side of the cost reduction estimates found in the literature. For instance, the International Energy Agency (IEA)'s 'Golden Age of Gas' scenario ${ }^{2}$ shows a $23 \%$ reduction by 2035 ; Newell and Raimi ${ }^{9}$ assumes a $45 \%$ reduction by 2040; the EMF 26 model comparison exercise's 'High Shale' scenario ${ }^{10}$ assumes a $21 \%$ reduction by 2035 ; and finally, the original GEA scenarios ${ }^{12}$ assumed a $33 \%$ reduction by 2050 . Although direct comparison is difficult owing to each scenario's differences in design, measurement, and time frame, our aggressive assumption is intended to represent a lower bound for future gas production costs.

The cost reduction assumption is also more aggressive than that of relatively mature low-carbon energy sources such as nuclear power plants, but not necessarily more aggressive compared to that of immature technologies such as solar photovoltaics (see Extended Data Table 1 for cost reduction comparison with other energy sources).

When the abundance in quantity and reduction in production cost are combined, the Abundant Gas supply curve allows 31,000 EJ of cumulative natural gas production at $\$ 3$ per GJ or less by 2050 . Extended Data Fig. 2 shows the reduction in cost from 2010 (red curve) to 2050 (blue curve). These production costs are different from the actual prices in the market place. The costs do not include taxes or royalties, nor do they include external environmental or social costs associated with gas production ${ }^{12}$

GCAM and MESSAGE models further tested sensitivity to the magnitude of production cost reductions. GCAM is a model relatively less sensitive to Abundant Gas supply, while MESSAGE is a model relatively more sensitive to it. The two models projected a total of five natural gas supply scenarios: (1) the Conventional Gas scenario; (2) the Abundant Gas scenario (at the standard 50\% cost reduction); (3) the Abundant Gas scenario (with the high cost reduction of 75\%); (4) the Abundant Gas scenario (with the low cost reduction of 25\%); (5) the Abundant Gas scenario (with the zero cost reduction, abundant in quantity only).

The results are shown in Extended Data Fig. 3. Collectively, these scenarios cover a wide range of cost reduction found in the literature. Our core finding from the main analysis is found to be consistent with results from this sensitivity. In all cases considered, we found that more abundant natural gas could substantially change the global energy system over the decades ahead without producing commensurate changes in emissions or climate forcing

GCAM reported $+13 \%$ to $+82 \%$ additional natural gas consumption in 2050 while the change in $\mathrm{CO}_{2}$ emissions is found to be in the $-0.9 \%$ to $-2.0 \%$ range and the change in radiative forcing is found to be in the $+0.3 \%$ to $+1.1 \%$ range. MESSAGE reported $+56 \%$ to $+170 \%$ additional natural gas consumption in 2050 , while its change in $\mathrm{CO}_{2}$ emissions is found to be in the $-1.0 \%$ to $+0.6 \%$ range and its change in radiative forcing is found to be in the $+0.7 \%$ to $+3.4 \%$ range.

Just as in the main analysis, the models did not agree on the direction of the impact on $\mathrm{CO}_{2}$ emissions. GCAM consistently reported lower $\mathrm{CO}_{2}$ emissions with respect to lower cost assumptions. MESSAGE reported that the $\mathrm{CO}_{2}$ emissions increase at the high end of the cost reduction range. However, these changes are very small, with a magnitude less than $2 \%$ of the total emissions. Once we consider the combined effect of all greenhouse gases, the two models consistently agree on the direction of the change: the lower the natural gas production cost, the higher the total radiative forcing and associated temperature change. Our main finding that increased use of abundant gas does not produce a discernible reduction effect on climate forcing is found to be consistent across the range of cost reduction sensitivities.
Main analysis. The main analysis presented in the paper may be sensitive to a range of model assumptions. We reported two of the core sensitivities in the main text. Here we describe detailed methodologies for the main analysis and the sensitivity analyses.

The main analysis follows a standard method for IAM study on baseline scenarios. The five models are explicitly designed to project the future emissions trajectory under various assumptions about the energy system and the economy. Representing the energy and economic system in an abstract structure, IAMs provide a simulation method of conducting an analysis when a 'controlled experiment' in the strict sense is not possible. Similar to a controlled experiment, our numerical experiment keeps all other parameters constant and varies only the natural gas supply curve. We then simulate the effect of market forces on the energy system evolution through 2050. From the two simulations that differ only in terms of natural gas supply, we report the differences in the output variables, such as energy system composition, emissions, and climate forcing. Such differences in output variables are directly attributable to the differences in input variables.

To closely replicate the human system dynamics, each model calibrates its parameters to the observed data in the historical years. The data used for calibration is reported in the model descriptions. Calibrated parameters include technological parameters such as energy production efficiency and emissions intensity, economic parameters such as price elasticities and income elasticities, and non-market parameters such as regional preferences for specific fuel type or preferences for a specific mode of travel. Projecting into the future, some parameters are assumed to improve over time (for example, energy production efficiency) and others are assumed to be constant (for example, social preferences for a specific mode of travel are assumed to be constant).

As this is a baseline scenarios study, we did not assume any explicit climate change mitigation policies. This study addresses the following question: if there are no new policies to mitigate climate change, does increased use of abundant natural gas reduce greenhouse gas emissions? However, although no economy-wide climate change mitigation policy has been currently implemented, the currently existing policies that have been implemented in the past would affect the parameters calibrated to historical observations. For instance, the Corporate Average Fuel Economy (CAFE) standard in the USA has been enforced since 1978 to increase the fuel economy of cars and decrease fuel consumption. Although this was not explicitly intended as a climate change mitigation policy, it has had the side-effect of reduced emissions per distance travelled. This side-effect would be implied in the calibration process and propagate forward into the future. As a result, the future projection of emissions would be lower than they would otherwise have been without the CAFE standard in effect.

Similarly, any energy policies that were enforced before the calibration periods would affect the calibration parameters. These include Renewable Fuel Standard policies that mandate the ratio of biofuels in gasoline, building energy standards that mandate the minimum efficiency levels of building shells, and renewable or fossil fuel energy subsidies. These policies affect the implied preference for certain energy sources or efficient equipment. However, we do not include the policies that are proposed, but not currently in effect. For studies that do include proposed policies in their scenarios, see refs 31 and 32 . Next, we describe one sensitivity analysis that explicitly represents a future energy policy that is currently not included in the calibration.

Abundant gas exclusively substitutes coal scenario. In our main analysis models allow natural gas to substitute not only for coal, but also for a range of energy sources including solar, wind, nuclear, and bioenergy. These substitutions are driven by the economic competitiveness of each fuel type. However, it is also possible to imagine a policy architecture in which a normative policy protects low-carbon energy sources, thus effectively forcing additional natural gas to exclusively substitute coal. Under such restrictions, we expect overall $\mathrm{CO}_{2}$ emissions to decrease. To estimate the magnitude of the sensitivity to the substitution restriction, we assume a future where low-carbon energy sources are protected by a globally enforced Clean Energy Standard. In this scenario, natural gas is assumed to exclusively substitute for coal.

First, we assume that the low-carbon energy quantity is fixed at the same level as the Conventional Gas scenario. Then, we calculate the quantity difference in lowcarbon energy between the Conventional Gas and Abundant Gas scenarios; this is the amount of low-carbon energy that would be protected under the policy. To keep the scale of energy system unchanged, we assume the same amount of coal is instead substituted by additional gas. The total amount of gas consumption remains unchanged. We then apply the emissions factors from Extended Data Table 3 and recalculate the additional emission reduction.

With the exception of BAEGEM, all models show that the 'coal substitution only' assumption results in emission reductions in 2050, ranging from $-0.1 \%$ (WITCH) to $-5.9 \%$ (MESSAGE). See Extended Data Table 2 for the range of values. Compared to the emissions changes in the main analysis, in which the majority of the 
models showed positive emissions increase, the 'coal substitution only' scenario shows that under certain policy conditions, abundant gas could help reduce $\mathrm{CO}_{2}$ emissions.

In the case of BAEGEM, the lower gas prices accelerate economic activity, such that the overall energy system is $11 \%$ larger in the Abundant Gas scenario. The 'coal substitution only' assumption does reduce the average emission intensity of the energy system, but the energy system expansion effect still dominates, such that the total emission is still larger than in the Conventional Gas scenario.

High fugitive methane emissions scenario. The fugitive methane emission rate is subject to large uncertainty. The rates used in the five models all fall within the range $0.3-0.6 \mathrm{~kg}$ of $\mathrm{CH}_{4}$ per GJ (Extended Data Table 3). These values are similar to the values reported in conventional literature ${ }^{23,24,33}$. However, some recent literature suggests that the fugitive methane rate may be substantially higher by up to a factor of four ${ }^{7,27,28}$. To test our results' sensitivity to high fugitive methane rates, we select the upper bound of fugitive methane estimates (7.9\%) found in the literature and re-estimate the climate forcing.

We start from the original emission trajectories from each model. Then, while keeping all else equal, we recalculate the methane emission trajectory by applying the high fugitive methane emission rate to the natural gas use. These modified emission trajectories are then reprocessed through the common climate model MAGICC6. With the high fugitive methane assumptions, the abundant gas increases the total anthropogenic radiative forcing by $0.2 \%$ to $12 \%$ in 2050 , which is $0.5 \%$ to $5 \%$ points higher than under the standard assumptions. A full comparison is shown in Extended Data Table 4.

IAMs of energy-economy-climate systems. The five models that are used in this study are members of a class of models referred to IAMs. IAMs in general encompass the broad suite of human and natural Earth systems including the economy, energy, agriculture, land-use, land cover, and biogeophysical processes from carbon and hydrologic cycles, the atmosphere, oceans and climate ${ }^{11}$. The five models employed in this study are well equipped to assess the impact of abundant natural gas on climate forcing. Each contains a state-of-the-art energy-economy systems model coupled to a simple climate model.

Each of the five models represents energy and economic systems differently. Below, we provide a general description of the strengths and limitations the five models bring to the issue of assessing the impact of abundant natural gas on climate forcing. This is followed by more detailed descriptions of the five models. The IAMs of energy-economy-climate systems employed in this study bring a number of strengths to the issue of the global long-term climate forcing implications of abundant natural gas. In general, the models were designed to address precisely the kind of problem we explore in this paper. They have the appropriate geographic, temporal, and sectoral coverage.

All of the models explicitly represent processes that start from the extraction of primary energy (exhaustible fossil fuels and renewable energy) to energy transformation (for example, liquid fuel refineries and power generation) to end-use services (buildings, industry, and transport). The models feature explicit representation of energy markets with price-responsive demand and supply for coal, oil, and gas as well as low-carbon energy sources ${ }^{20,34}$. The flexibility and interdependence of energy markets are crucial for the present study because these features determine the degree to which additional natural gas is consumed and by how much this reduces the demand for other fuels. All five models employ a standard economic paradigm in their representation of energy markets. Price is the principal force determining and equilibrating the supply of and demand for different fuels.

IAMs vary in a number of important ways. While all of the models in this study have explicit representations of both the economic system and the energy system, they vary in terms of their relative emphasis on representing the details of the two interlinked systems. Model structures that emphasize economic interactions across all sectors of the industry are particularly strong for examining how changes in one industry propagate through the whole economy. These models are also strong in examining changes in international trade patterns due to region-specific changes in industrial structure. BAEGEM ${ }^{13}$ is one example of this type of model with 25 explicit sectors of the economy each consuming a bundle of energy sources, where the share of the bundle is determined by the relative prices.

In contrast, GCAM ${ }^{14}$ and MESSAGE ${ }^{35}$ place greater emphasis on representing the details of the physical energy system. They contain detailed representations of key energy systems and technology options for producing, transforming and using energy, while adopting more aggregate representations of the broader economy. GCAM and MESSAGE have more than 100 different energy supply and conversion technology representations. This approach is more rigid in the ability to substitute between the factors of production, namely capital/labour inputs and energy inputs, compared to the approach used by models such as BAEGEM. However, it can better capture the physical details of individual services provided in the end-use sectors, such as ton-kilometres of freight or GJ of residential heating. This modelling approach is particularly strong for in-depth analysis of a specific energy technology and tracking the physical flows of energy goods and services.
REMIND $^{36}$ and WITCH ${ }^{17}$ lie between BAEGEM on the one end and GCAM and MESSAGE on the other. These models have more detail in their economic structure and less energy system detail than the latter, but more energy system detail and less economic system detail than the former.

Another domain in which the models vary is their assumption about the knowledge and behaviour of their economic agents. Intertemporal optimization models represent economic agents that maximize their economic utility over the model time horizon. The agents are assumed to know future price changes with certainty and hence the resulting model solution is economically optimal for each agent MESSAGE, REMIND, and WITCH employ this method.

On the other hand, GCAM and BAEGEM takes a more descriptive approach where the economic agents are assumed to not know the future price changes, but rather make production and consumption decisions based only on the information available to them at any given time. This approach provides insights about how the system might be expected to evolve under imperfect information about the future. However, the resulting equilibrium trajectory may not be economically optimal.

Modelling paradigm for IAMs. The variety in modelling approaches used by the five models in this exercise strengthens this analysis. This diversity guards against a result that is the product of an individual model's idiosyncratic behaviour. To the extent that models employ different methodologies and get qualitatively similar results, we have greater confidence in the result. That said, all models subscribe to the standard economics paradigm. Other modelling paradigms exist, such as adaptive agent models, system dynamics models, or infrastructure models. We have not tested these modelling paradigms in this paper. As such, the models do not span the full range of all possible methods that could potentially be employed to assess the impact of more abundant natural gas for climate forcing.

One limitation of the models employed in this study is that they do not model explicit locations of physical infrastructure. The geographic locations of present and future natural gas pipelines and liquefied natural gas terminals are modelled at coarse international resolution, and do not take into account detailed local information that shapes decisions about which facilities are deployed, and where and how they are connected to the broader system. Geographically resolved infrastructure models can potentially include this level of detail. However, infrastructure models are relatively static in nature and are therefore generally not employed to model the global energy system's evolution over multiple decades into the future.

Also, the five models are built on the foundation of the standard economic paradigm, and they do not, for instance, employ an adaptive agent modelling approach or systems dynamics approach. Future research could employ a broader suite of modelling methods to shed further light on the implications of abundant natural gas for climate forcing, and examine whether other modelling approaches would yield a qualitatively different result.

Representing the policy environment in IAMs. The energy policy environment exerts a strong influence on energy production and use and thereby on climate forcing. Our default assumption is that no new policies and measures are introduced after the calibration period. Alternative assumptions can produce different results for energy, for the economy and for climate forcing. We tested one energy policy that can potentially change the results. We found that exogenously specifying the quantity of low-carbon energy sources and forcing natural gas to substitute exclusively for coal results in emissions being reduced in the models.

Other policies, such as carbon tax, cap-and-trade, or natural-gas vehicle subsidies, could alter our results. The climate implications of abundant gas under climate policies are of great interest. However, the issue is sufficient in scope and depth to require its own future research, and hence is not addressed here.

Baseline assumptions in IAMs. Finally, we point out that the numerical simulations of the effects of increased natural gas availability that we have performed for this paper are all based on each model's native reference scenario assumptions. Those scenarios are each developed by the modelling teams themselves and no attempt was made to harmonize assumptions other than natural gas supply curves. This was intentionally done to increase the variety of conditions against which the implications of abundant gas would be assessed.

Specifying different exogenous assumptions would produce different results. Some perturbations have well established consequences common to all of the models For example, higher population growth or higher rates of economic productivity growth increases the scale of the energy system overall. Perturbations in the assumed rate at which technological change that occurs in low-carbon technologies would change the future emission intensity of the energy system.

While we have not attempted to explore the sensitivity of our results to variation in those assumptions, the five models' native assumptions cover a wide uncertainty range consistent with the large majority of the literature ${ }^{37}$, but they do not cover the extremes found in the literature (see Extended Data Fig. 4). Examining the four principal components of model projections (population, gross domestic product (GDP), energy consumption, and $\mathrm{CO}_{2}$ emissions), we observe that the five models 
cover most of the 10th to 90th percentile range for population and GDP in 2050 . The projected ranges for energy consumptions and $\mathrm{CO}_{2}$ emissions are narrower, but cover most of the 25th to 75 th percentile range. To the extent that the five models report qualitatively similar results despite the large variations in baseline assumptions, we have greater confidence in the results.

Uncertainties in IAMS. Uncertainty attends every element of the modelling process. There are two major elements of uncertainty in the modelling system: model structure and model input assumptions (future population, economic activity, technology and policy). Methods have been developed to address each of these uncertain elements. Uncertainty in model input assumptions are addressed in a variety of ways ranging from simple sensitivity analysis to formal uncertainty quantification analysis. Uncertainty in model structure is more difficult and model intercomparison is an important tool for exploring this source of uncertainty.

The formal Monte Carlo analysis ${ }^{38,39}$ employs a single model to process numerous samples of input variables, such as fossil fuel supply, economic growth, technological learning, and so on. The distribution of the output shows the range of uncertainty associated with the model results. For simple models, uncertainties associated with all model inputs can be examined. However, with the growing complexity of IAMs, this method is becoming increasingly difficult to implement.

Sensitivity analyses identify key variables of interest and examine each model's response to variation in those input values. We have identified three such variables and performed sensitivity analyses. We have also examined sensitivity to energy policy, specifically sensitivity to low-carbon energy policy. In this latter case we found that under a global low-carbon energy protection policy, the availability of more abundant gas can reduce climate forcing. We also explored the sensitivity of our results to the rates of fugitive methane emissions and found that with high fugitive methane emission rates, more abundant gas can discernibly increase climate forcing. Finally, we explored the sensitivity of model outputs to natural gas supply characterizations, specifically production cost, and found that our results were consistent across a wide range of natural gas supply assumptions.

Model intercomparison projects (MIPs), where a number of models simulate a common set of scenarios, are the primary method employed to explore the implications of variation in model structure, although they are also used to structure sensitivity and scenario analysis. The Energy Modelling Forum (EMF) ${ }^{10}$ has been conducting MIPs of energy-economy models since 1977. The MIPs conducted by EMF are analogous to the Coupled Model Intercomparison Project (CMIP) ${ }^{40}$ of the climate modelling community, where a larger number of climate models project the future climate and assess the distribution of the projection. MIPs can be though of as the modelling equivalent of scientific hypothesis testing using different methods. If a number of models with heterogeneous architecture reach a common conclusion, we can have greater confidence in that conclusion.

This study is an example of a MIP with a small number of models. The comparison of the results across the models shows large uncertainty. The uncertainty is especially large in the future level of natural gas consumption, and consequently the use of competing energies, such as solar photovoltaics and nuclear power plants. The uncertainty is also present in the size of the impact of abundant gas on the emissions. These results are highly dependent on model architecture and the implied flexibility of fuel-switching. However, the models all agree on the most potent conclusion: increased supply of abundant gas does not discernibly reduce either $\mathrm{CO}_{2}$ emissions or climate forcing. Some models report a discernible increase in emissions or climate forcing, and others report negligible change. But none of the models report more than a $2 \%$ reduction in emissions or climate forcing. This qualitative agreement across five heterogeneous models in this exercise gives greater confidence in the conclusion.

Overview of the BAEGEM model. BAEGEM ${ }^{13}$ is a recursively dynamic computable general equilibrium model of the world economy. For each one-year time step, BAEGEM simulates the interrelationships between economic growth, flows of international trade and investments, constraints on natural resources and production factors, greenhouse gas emissions and climate change policies.

The central core of BAEGEM is built on the familiar approaches of the GTAP mode $^{41}$, with the household consumption behaviour and the producer behaviour represented separately by a constant difference of elasticities function and a nesting of Leontief, constant elasticity of substitution (CES) and constant ratios of elasticity of substitution, homothetic (CRESH) functions ${ }^{42}$.

BAEGEM is written in GEMPACK ${ }^{43}$. The full model code is complemented by four interlinked modules: (1) the government module; (2) the technology mix module; (3) the energy module; and (4) the greenhouse gas emissions module. The model is ideally suited to analysing domestic and international energy-related policies, and the impacts of economic shocks.

The BAEGEM database is derived from a number of sources. The global social accounting matrix is derived from the GTAP version 8 database ${ }^{44}$ with a base year of 2007. To enhance the capability of modelling individual commodities, the number of commodity groups in BAEGEM has been expanded from 57 in the GTAP version
8 database to 72 . The disaggregated commodities include black thermal coal, brown coal, coking coal, iron ore, bauxite, copper ore, gold, uranium, titanium, zirconium, coke, nuclear fuel, alumina, copper, aluminium and liquefied natural gas.

The emissions database covers all Kyoto gases and is sourced from the International Energy Agency ${ }^{45,46}$, the United National Framework Convention on Climate $\mathrm{Change}^{47}$ and the US Environmental Protection Agency ${ }^{48}$. The data in the government module are sourced from Global Insight while the data in the technology mix and energy modules are sourced from the IEA.

The global temperature rise, total radiative forcing and the atmospheric concentration of carbon dioxide can be calculated from the BAEGEM results by linking to MAGICC $^{49}$, with climate sensitivity set to three degrees Celsius. BAEGEM natively links to MAGICC 5.3, but for this study we have used MAGICC 6.0 for latest scientific knowledge and consistency across models.

Supplementary Fig. 1 and Supplementary Table 1 provide an overview of the other key features of BAEGEM.

Modelling energy commodities in BAEGEM. The energy module tracks the production of primary and secondary energy, and the consumption of final energy by government, households and firms. Changes in production volume over the projection period are driven by global demand growth, which in turn is determined by real GDP growth, and changes in prices, consumption preference, market structure, sector productivity and market structure.

The government demand for each commodity is derived from a Cobb-Douglas function nested with Armington composites of commodities supplied by domestic and foreign sources. The household demand for each commodity is determined by the demand of a representative household and the growth in population. At the first level, the representative household chooses quantities of non-energy commodities and an energy composite (that is, coal, gas, refined petroleum product, electricity and heat) to maximize a utility function, given a budget constraint. At the next level, the representative household chooses quantities of energy commodities to minimize the cost of consuming the energy composite in the previous level. The purpose of this two-level demand system is to reflect better the substitutability between energy commodities with a more flexible substitution system.

Demands for energy commodities in each production sector are derived from a nesting of Leontief, CES and CRESH functions. At the first level, a Leontief technology links the input of factor-energy composite to the industry output level. At the second level, it is a CES cost minimization problem searching for an optimal combination of energy and factor composites where energy commodities and primary factors (that is, capital, labour, land and natural resources) are substitutable, but not perfectly so. For land and natural resource-intensive industries (that is, crops, livestock, coal, oil, and gas), a CES structure with imperfect substitutability ensures that constraints on land and natural resource or more intensive use of capital and labour under finite natural resources can be modelled properly in BAEGEM. At the third level, another cost minimization problem is specified, but here it searches for an optimal combination of energy commodities under a CRESH production function.

Electricity supply from various technologies is modelled inside the technology mix module. The 'technology bundle' approach ensures that electricity output can be produced from a bundle of individually identified generation technologies and that each technology uses a different mix of inputs. The purpose of integrating a bottom-up modelling approach for the electricity sector into BAEGEM is to represent better the technology-specific detail of the sector while retaining the benefits of the top-down interactions modelled in BAEGEM. In this application, the electricity output is the sum of nine technologies: coal; oil; gas; nuclear; hydro; wind solar; biomass; and others.

The substitution possibilities between electricity technologies in BAEGEM are governed by a CRESH aggregation function. CRESH is a generalization of CES and allows elasticity of substitutions to vary between its elements. In other words, certain technologies identified in the framework can be assumed to be more substitutable than others. The use of the family of CRESH aggregation functions allows for the fact that electricity, which is a homogenous output, can be generated in an economy simultaneously from different technologies with different production costs. Modelling greenhouse gas emissions in BAEGEM. The greenhouse gas module tracks Kyoto gas emissions (for $\mathrm{CO}_{2}, \mathrm{CH}_{4}, \mathrm{~N}_{2} \mathrm{O}$, HFCs, PFCs and $\mathrm{SF}_{6}$ ) over the course of production, transformation, consumption, and combustion. For each time step, emissions pathways of Kyoto gases are derived from the quantities of these economic activities and changes in emission factors. The projections of radiative forcing agents other than Kyoto gases are selected from emission scenarios in MAGICC according to modelling criteria, assumptions and applications. Supplementary Table 2 provides the list of the gases and the data sources for assigning emissions coefficients for each sector in BAEGEM.

BAEGEM assumes the constant proportionality of emissions with respect to the quantity of fossil fuel combusted over time. The disaggregated $\mathrm{CO}_{2}$ emissions for the base year is derived from the GTAP 8.0 database with adjustments to ensure 
that aggregate combustion emissions at country level are consistent with the IEA combustion emission database ${ }^{50}$.

Non-combustion emissions, such as fugitive emissions from fossil fuel mining enteric fermentation in livestock production and chemical transformation in manufacturing processes, are assumed to change in proportion to their production levels adjusted by EMF21 marginal abatement curves ${ }^{51}$. The use of marginal abatement curves in the module allows a gradual reduction of non-combustion emissions per unit of output with additional reduction opportunities when carbon price increases. The disaggregated non- $\mathrm{CO}_{2}$ emissions for the base year is derived from the US Environmental Protection Agency databas $\mathrm{e}^{48}$ and the GTAP 7.0 database with adjustments to ensure that aggregated non- $\mathrm{CO}_{2}$ emissions are consistent with the IEA non$\mathrm{CO}_{2}$ emissions database ${ }^{46}$

Overview of the GCAM model. GCAM is a global integrated assessment model of energy, economy, land-use, and climate. GCAM originates from the Edmonds and Reilly mode ${ }^{52-56}$. In this paper, we use the standard release of GCAM 3.1 with the natural gas system specifically modified to reflect the common assumptions on natural gas. GCAM is an open-source model ${ }^{14}$ primarily developed and maintained at the Joint Global Change Research Institute. The full documentation of the model is available at the GCAM wiki ${ }^{14}$, and the following description is a summary of the wiki documentation.

GCAM is a long-term global model with particular emphasis on the representation of human dimensions of the Earth system. GCAM integrates representations of the global economy, energy systems, agriculture and land use, with representation of terrestrial and ocean carbon cycles, and a suite of coupled gas-cycle and climate models (Supplementary Fig. 2).

The climate and physical atmosphere in GCAM is represented by MAGICC ${ }^{22}$. The emission trajectories of greenhouse gases are modelled in GCAM's energy and land-use components. GCAM is natively integrated with MAGICC 5.3, but for this study we have used MAGICC 6.0 for the latest scientific knowledge and consistency across models.

The global economy of GCAM is represented in 14 geopolitical regions, explicitly linked through international trade in energy commodities, agricultural and forest products, and other goods such as emissions permits. The scale of economic activity is driven by population size, age and gender, and labour productivity, which determine economic output in each region. The energy and land-use market equilibrium is established in each period by solving for a set of market-clearing prices for all energy and agricultural good markets. This equilibrium is dynamic-recursively solved for every five years in the period 2005-2100. Supplementary Table 3 provides an overview of the other key features of GCAM

Modelling energy system and natural gas in GCAM. In GCAM, the energy system represents processes of energy resource extraction, transformation, and delivery, ultimately producing services demanded by end users. Resources are classified as either depletable or renewable; in either case, the extraction costs of a given resource are assumed to increase as economically attractive resources are employed, but are also subject to technological progress which can lower extraction costs for a given resource grade. In each time period, the market prices of energy goods and services, including fossil fuel resources, are determined within the market equilibrium.

Fossil fuel energy is produced from a graded, regionally disaggregated depletable resource base. Renewable energy forms are also disaggregated by region and resource grade; however, by their nature, the resource is not consumed by use. Primary energy forms can be transformed into final energy products, including electricity, processed gas products, refined liquids, and so on.

Energy transformation sectors convert resources initially into fuels consumed by other energy transformation sectors, and ultimately into goods and services consumed by end users. Multiple technologies compete for market share; shares are allocated among competing technologies using a logit choice formulation ${ }^{57}$. The cost of a technology in any period depends on two key exogenous input parametersthe non-energy cost and the efficiency of energy transformation-as well as the prices of the fuels it consumes. The non-energy cost represents all fixed and variable costs incurred over the lifetime of the equipment (except for fuel costs), expressed per unit of output. For example, a gas-fired electricity plant incurs a range of costs associated with construction (a capital cost) and annual operations and maintenance. The efficiency of a technology determines the amount of fuel required to produce each unit of output. The prices of fuels are calculated endogenously in each time period based on supplies, demands, and resource depletion. The depletion of economically available energy resources is explicitly tracked throughout the modelling period.

The natural gas resource supply curves for the two scenarios are based on synthesis by the GEA ${ }^{12}$, as described above. In GCAM, natural gas can be used for direct combustion in the end-use sectors or converted into other energy forms, such as electricity hydrogen or refined liquids, before being consumed in the end-use sectors. Direct combustion and conversion to other forms both result in $\mathrm{CO}_{2}$ emissions. The physical quantity of carbon is preserved throughout the energy system process. Once natural gas is extracted, the carbon in the fuel is either emitted or sequestered. Non- $\mathrm{CO}_{2}$ emissions are tracked separately. The next subsection describes the treatment of non- $\mathrm{CO}_{2}$ emissions in detail.

Modelling greenhouse gas emissions in GCAM. GCAM tracks 16 different greenhouse gases, aerosols and short-lived species. Supplementary Table 4 provides the list of the gases and the data sources for assigning emission coefficients for each sector in GCAM.

Fossil fuel $\mathrm{CO}_{2}$ emissions are modelled according to the following method: (1) The total emission in the base year is calibrated to the Carbon Dioxide Information Analysis Center database ${ }^{58}$. (2) The fossil fuel consumption in the base year is calibrated to the IEA's Energy Balances Database ${ }^{59,60}$. (3) The average emission coefficients are derived from the ratio of the total emission and the total fuel consumption for each fuel (coal, oil, and gas). (4) These emission coefficients are applied to each sector in the base year. (5) For future periods, GCAM solves for market shares of each fuel in each sector, and the emissions are calculated to be the product of emission coefficients and the fuel consumption in each sector.

Non- $\mathrm{CO}_{2}$ gases in the energy system are calculated according to the following method: (1) The total emission for each gas in the base year is calibrated to the RCP data $^{18,61}$. (2) Emissions by each sector in GCAM are compiled from the databases listed in Supplementary Table 4. (3) The individual emission coefficients for the base year are calculated by scaling the individual sector emissions to match their sum to the total emissions. (4) For future periods, GCAM solves for market shares of each technology in each sector, and the emissions are calculated by the product of emission coefficients and the technology usage level in each sector. (5) Future emission coefficients are assumed to improve over time with economic growth based on Energy Modelling Forum Study $21^{48,51}$.

Extended Data Table 3 shows the calculated emissions coefficients of $\mathrm{CO}_{2}$ and $\mathrm{CH}_{4}$ emissions for each fossil fuel. Fugitive $\mathrm{CH}_{4}$ emission for natural gas is modified in the sensitivity analysis to reflect the wide range of estimates in the literature. Overview of the MESSAGE model. MESSAGE ${ }^{35,62,63}$ is a linear-programming systems engineering optimization model used for medium- to long-term energy system planning and policy analysis. The model minimizes total discounted energy system costs, and provides information on the utilization of domestic resources, energy imports and exports and trade-related monetary flows, investment requirements, the types of production or conversion technologies selected (technology substitution), pollutant and greenhouse gas emissions, and inter-fuel substitution processes, as well as temporal trajectories for primary, secondary, final, and useful energy.

MESSAGE stands at the core of the IIASA integrated assessment framework ${ }^{15}$, which combines a blend of different models to represent the global economy and the interactions between energy, agriculture, and forest sectors and their implications for greenhouse gas emissions and associated climate responses.

MESSAGE is linked to the macro-economic model MACRO for assessing economic feedbacks and price-induced changes of energy demand ${ }^{62}$. In the form used here, MACRO has its roots in a long series of models by Manne and Richels, the latest of which is MERGE 5.164. MACRO's objective function is the total discounted utility of a single representative producer-consumer (for each of its 11 world regions). The maximization of this utility function determines a sequence of optimal savings, investment, and consumption decisions. In turn, savings and investment determine the capital stock. The capital stock, available labour, and energy inputs determine the total output of an economy according to a nested CES production function. Energy demand in six categories (industry electric and thermal, residential electric and thermal, transport and non- energy use) is determined within the model, consistent with the development of energy prices and the energy intensity of GDP. When MACRO is linked to MESSAGE, internally consistent projections of GDP and energy demand are calculated in an iterative fashion that takes price-induced changes of demand and GDP into account. This is achieved through iterations between the two models, in which demand, energy system costs and energy prices are exchanged until the solution of both models converge. For details of the iterative model linkage, see ref. 62 .

In addition to the energy sector, MESSAGE represents the greenhouse gas emissions from land-use changes in the agricultural and forest sector. For the calculation of physical climate responses, MESSAGE is coupled with MAGICC ${ }^{65}$. MESSAGE is natively integrated with MAGICC 5.3, but for this study we have used MAGICC 6.0 for the latest scientific knowledge and consistency across models. Supplementary Table 5 provides an overview of the other key features of MESSAGE.

Modelling energy system and natural gas in MESSAGE. A typical model application is constructed by specifying performance characteristics of a set of technologies and defining a Reference Energy System that includes energy technologies and flows along the entire energy chain. In the course of a model run MESSAGE determines how much of the available technologies and resources is actually used to satisfy a particular end-use demand, subject to various constraints, while minimizing total discounted energy system costs. A simplified illustration of the MESSAGE Reference Energy System is shown in Supplementary Fig. 3. 
The representation of the energy system includes explicit tracking of the longlived energy infrastructure by vintage, which allows for consideration of the timing of technology diffusion and substitution, the inertia of the system for replacing existing facilities with new generation systems, clustering effects (technological interdependence) and possible phenomena of increasing returns (that is, the more a technology is applied the more it improves and widens its market potentials). Combined, these factors can lead to 'lock-in' effects ${ }^{66,67}$ and path dependency (change occurs in a persistent direction based on an accumulation of past decisions). As a result, technological change can go in multiple directions, but once change is initiated in a particular direction, it becomes increasingly difficult to change its course.

Important inputs for MESSAGE are technology costs and technology performance parameters. For the scenarios included in this paper, technical, economic and environmental parameters for over 100 energy technologies are specified explicitly in the model. Costs of technologies are assumed to decrease over time as experience (measured as a function of cumulative output) is gained. Assumptions for the main energy conversion technologies are summarized in ref. 68. The regional energy costs are based on IEA ${ }^{69}$. For carbon capture and storage technologies, the power sector applications are based on ref. 70 and the liquid conversion processes are based on refs 71-73. Biomass technology costs are based on ref. 71. For the evolution of technology costs over time we adopt the assumptions of the GEA-Mix scenario of the Global Energy Assessment ${ }^{74}$.

Fossil fuel resource estimates and potentials for renewable energy are another important set of input parameters. For fossil fuel availability the model distinguishes between conventional and unconventional resources for different categories of oil, gas, or coal occurrences ${ }^{75}$. With regard to volumes for coal and oil we mainly follow the quantitative assumptions adopted by the $\mathrm{GEA}^{76}$. Resource assumptions for natural gas are different across the scenarios in this paper and were specifically updated from ref. 12 to represent 14 different occurrences of natural gas for each of the 11 MESSAGE regions. Energy losses (own use) of natural gas extraction are modelled explicitly and range from close to zero up to $25 \%$ of the extracted gas, depending on the type of natural gas occurrence. Fugitive $\mathrm{CH}_{4}$ emissions from natural gas extraction are assumed to be between close to zero to $5 \%$ of the extracted natural gas and increase for unconventional gas resources. Assumptions about energy losses and fugitive emissions are based on ref. 77. For renewable energy resource potentials we rely on spatially explicit analysis of resource availability and adopt the assumptions discussed in ref. 68

Representation of natural gas infrastructure in the MESSAGE model comprises explicit technologies for extraction, transmission and distribution, trade, conversion and use of natural gas in appliances of various service sectors. Main energy conversion technologies include various types of power generation technologies, heat generation (including combined heat and power facilities), hydrogen generation, and gas-to-liquid supply chains. Intra-regional trade options include piped gas as well as liquefied petroleum gas. Natural gas consumption of end-use appliances are modelled at the level of three main energy end-use sectors, including residential and commercial, industry and the transport sector. $\mathrm{CO}_{2}$ emissions are modelled along the conversion chain and are either vented to the atmosphere or sequestered underground in the case of carbon capture and storage.

Modelling greenhouse gas emissions and $\mathrm{CH}_{4}$ in MESSAGE. In addition to $\mathrm{CO}_{2}$ emissions, the MESSAGE model considers the full basket of non- $\mathrm{CO}_{2}$ greenhouse gases $\left(\mathrm{CH}_{4}, \mathrm{~N}_{2} \mathrm{O}\right.$, and F-gases) as well as emissions from other radiatively active substances from the energy, industrial and non-energy sectors of the economy (disaggregated at each of the model's eleven regions). These include particulate matter (PM2.5), sulphur dioxide $\left(\mathrm{SO}_{2}\right)$, nitrogen oxides $\left(\mathrm{NO}_{x}\right)$, volatile organic compounds (VOC), carbon monoxide (CO), black carbon (BC), organic carbon (OC), and ammonia $\left(\mathrm{NH}_{3}\right)$. Representation of non- $\mathrm{CO}_{2}$ gases in MESSAGE is described in detail in ref. 63. Here, we primarily focus on $\mathrm{CH}_{4}$.

$\mathrm{CH}_{4}$ emissions are calibrated for the base-year to the RCP inventory ${ }^{18}$. The model represents $\mathrm{CH}_{4}$ sources by linking appropriate emission coefficients to various activity variables in the model. These include coal, oil and gas extraction and transportation; and energy-related fossil fuel and biomass combustion. We assume gradual technological improvements in regions with high coefficients for these energyrelated sources, such as reduced future pipeline leakage in the gas sector in the form of decreased emission coefficients. As explained earlier, in the extraction sector emissions coefficients are different across different natural gas occurrences, and emissions can thus increase when shifting from conventional to unconventional occurrences.

For livestock- and agriculture-related $\mathrm{CH}_{4}$, sector-specific drivers are used to project emissions into the future, whereas emissions factors decline for these sources over time, consistent with the projected productivity improvements in livestock management and agricultural production ${ }^{78}$.

For $\mathrm{CH}_{4}$ emissions from solid waste, we use IPCC country-specific mass-balance methodology ${ }^{79}$ to obtain estimates of current emissions. We then examine longterm trends in waste generation rates, recycling, and gas recovery to develop longterm emissions. Based on land availability constraints and current trends in most developed countries, the rates of recycling and incineration are assumed to increase around the world, thus leading to a lower share of waste on landfills.

MESSAGE considers also the recovery of $\mathrm{CH}_{4}$ in energy and non-energy sectors. In the energy sector $\mathrm{CH}_{4}$ may be captured from coal mining (through degasification systems) which is fed into the energy system. In the solid waste sector, the recovered $\mathrm{CH}_{4}$ from landfills can be used as gas by the industrial sector or converted to electricity for end use. The resulting $\mathrm{CH}_{4}$ emissions factors of different fossil fuels are shown in Extended Data Table 3.

Overview of the REMIND model. REMIND is a global multi-regional model of the energy-economy-climate system spanning the period 2005-2100, with 5-year time steps between 2005 and 2060, and 10-year time steps thereafter. The periods 2005 and 2010 are used for calibration purposes. The scenarios start to differ from 2015 onwards. The world is divided into 11 regions: five individual countries (China, India, Japan, United States of America, and Russia) and six aggregated regions formed by the remaining countries (the European Union, Latin America, sub-Saharan Africa without South Africa, a combined Middle East/North Africa/Central Asia region, other Asia, and the rest of the world).

The macro-economic core of REMIND is an intertemporal general equilibrium model of economic growth with perfect foresight that is solved using optimization methods to compute the market equilibrium with full cooperation between regions. This approach is similar to RICE $^{80}$ and MERGE ${ }^{64}$. The macro-economic production function takes as input capital, labour and final energy. The resulting economic output is then available for investments into the macro-economic capital stock as well as for consumption, trade of goods, and financing the energy system. Macroeconomic consumption, exogenous population and the pure rate of time preference of $3 \%$ per year determine the welfare in each region.

An overview of the REMIND model is shown in Supplementary Fig. 4. The main features are summarized in Supplementary Table 7. The model has been published in the academic literature ${ }^{81-83}$ and a full model description is available online $e^{36}$

The REMIND model participated in a number of model comparison studies ${ }^{30,83-85}$ The energy sector and its sub-components have been reviewed in a number of model comparison studies. REMIND performed reasonably compared to the other participating models. REMIND showed particular strength in the sensitivity of pricequantity changes on fossil fuel markets and the international trade of fossil fuels ${ }^{29,86}$ Modelling energy systems and natural gas in REMIND. The energy system is hardlinked to the macro-economic core via final energy demand and costs incurred by the energy system ${ }^{86}$. Final energy demand is represented by a production function constant elasticity of substitution (nested CES production function) and includes transport energy, electricity, and various non-electric energy types for stationary end uses. This means that final energy demands are price responsive depending on the substitution elasticities.

The energy sector supplies final energy. The conversion of primary energy into secondary energy carriers as well as the distribution of secondary energy carriers to end-use sectors is represented by capacity stocks of more than 50 technologies in which costs of investment and operation and maintenance are also accounted for. System inertias are represented via the vintage capital structure and adjustment cost for accelerating capacity ramp-up. Therefore, primary energy demands are price elastic and depend on price-elastic final energy demands, all relative prices and system flexibilities in the energy sector. The price-responsive primary energy demands are crucial for the results of this study derived with the REMIND model. The effect of additional gas supplies acts on highly interdependent energy markets and price responsive energy demands are the main trigger for second-order effects due to the gas supply expansion.

The supply side of exhaustible primary energy sources (coal, oil, gas and uranium) assumes cumulative extraction cost functions in each region. In addition to the cumulative extraction cost function the fossil fuel extraction sector distinguishes different grades with an upper limit of supply, specific extraction costs and decline rates. The intertemporal general equilibrium, therefore, reflects producer rents and scarcity rents of the fossil fuel extraction sector. Major subsidies for fossil fuels are also reflected ${ }^{87}$. Natural gas can supply the power sector and supply gases for stationary use reflecting the residential, the service and the industry sector. The fossil fuel sector ${ }^{16}$ and the nuclear power sector ${ }^{82}$ are fully documented elsewhere. The supply of renewable primary energy comprises renewable energy potentials (biomass, hydro power, wind power, solar energy, and geothermal energy). Renewable energy and storage technologies feature technology learning, reducing investment costs with increasing installed capacity. Furthermore, the integration of fluctuating renewables is subject to integration costs that are implying diminishing returns depending on the market share. Bio-energy supply and land-use emissions are consistent with the land-use model MAgPIE ${ }^{88}$.

International trade is explicitly represented assuming a world market for final goods and primary energy carriers (fossil fuels, uranium and bio-energy). Importers and exporters of primary energy have to pay trading costs, which induce regional price differentials. For the case of natural gas trading costs are substantial and also 
energy losses for the transportation are considered. Trading costs are a crucial factor for the diverse development of regional energy systems. A major shift from conventional to abundant gas triggers a change of the relative geo-spatial distribution of gas endowments. In the abundant gas case the endowments are not only larger, but also geographically more evenly distributed, which improves domestic gas supply in many regions that are considered major importers in the conventional gas case.

Modelling greenhouse gas emissions in REMIND. Finally the model calculates energy related $\mathrm{CO}_{2}$ and non- $\mathrm{CO}_{2}$ greenhouse gas (for example, $\mathrm{CH}_{4}$ and $\mathrm{N}_{2} \mathrm{O}$ ) as well as aerosol emissions via time-dependent emission factors (see Supplementary Table 8). Regarding $\mathrm{CH}_{4}$ emission factors of extraction activities, they are differentiated for fossil fuels and regions but remain constant over time (see Extended Data Table 3). The marginal abatement cost functions map marginal abatement costs to relative reduction from the baseline level and are linearly scaled with the activity-dependent baseline. These time-dependent marginal abatement cost curves are employed to inform the model about mitigation solutions that prevent $\mathrm{CH}_{4}$ leakages and make this gas available for supply. Hence, as gas prices increase over time by moving to higher cost deposits, the incentive to invest in mitigation technologies increases and so $\mathrm{CH}_{4}$ emission factors are effectively reduced. The strength of the effect depends on the endogenous gas price. The greenhouse gas emissions representation in the REMIND model has been fully reported in the peer-reviewed literature ${ }^{89}$.

Overview of the WITCH model. WITCH ${ }^{17}$ is a dynamic global model that integrates the most important elements of climate change in a unified framework. The economy is modelled through an inter-temporal optimal growth model which captures the long-term economic growth dynamics. A compact representation of the energy sector is fully integrated (hard linked) with the rest of the economy so that energy investments and resources are chosen optimally, together with the other macroeconomic variables. Land-use mitigation options are available through a soft link with a land-use and forestry model (GLOBIOM $)^{90}$. Emission scenarios are processed through a simple climate model calibrated to MAGICC $6{ }^{22}$ to compute future climate outcomes. Climate change impacts on the economic output are captured through a damage function, accounting for implicit adaptation decisions. Explicit investment in additional adaptation efforts can reduce the damages associated with temperature change. Feedback loops between economy and climate are thus fully integrated in WITCH to simulate the intertemporal trade-offs between costs of climate change mitigation, adaptation, and residual damages.

WITCH represents the world in a number (currently 13) of representative native regions (or coalitions of regions); as shown in Supplementary Fig. 5, for each it generates optimal mitigation and adaptation strategies for the long term (2005 to 2100 ), as a result of a maximization process in which the welfare of each region (or coalition of regions) is chosen strategically and simultaneously to other regions. This makes it possible to capture regional free-riding behaviours and strategic interaction induced by the presence of global externalities. In this game-theory set-up, regional strategic actions interrelate through greenhouse gas emissions, dependence on exhaustible natural resources, trade of oil and carbon permits, and technology research and development. The endogenous representation of research-anddevelopment diffusion and innovation processes constitutes a distinguishing feature of WITCH. This approach gives the possibility to explore how research-anddevelopment investments in energy efficiency and carbon-free technologies integrate the currently available mitigation options. The model features multiple externalities, both on the climate and the innovation side. The technology externality is modelled via international spillovers of knowledge and experience across countries and time ${ }^{91,92}$. This formulation of technical change affects both decarbonization as well as energy savings. Supplementary Table 9 provides an overview of the other key features of WITCH.

Modelling energy system and natural gas in WITCH. In WITCH, the energy sector is fully integrated with the rest of the economy. It is distinguished in an electric sector, a transportation sector, and an aggregated non-electric (industry and residential) sectors. The energy sector is described by a production function that aggregates different factors at various levels and with associated elasticities of substitution. All the main energy carriers and technologies are included.

Natural gas is used in the industry and residential sector as well as for generating electricity. Gas power is available with and without carbon capture and storage. WITCH also tracks $\mathrm{CH}_{4}$ emitted in the non-energy sector. The marginal price of natural gas, along with the other energy carriers, is determined by cumulative global extraction and available resources. Natural gas is traded among the 13 regions, which can buy or sell it from a common pool. Bilateral trade across each region couple is not accounted for. This requires the modeller to vet the trade pattern results carefully when modelling regionally heterogeneous effects. However, this poses little problem in a world of abundant gas availability, where the global gas market is expected to be more integrated and the role of bilateral contracts to be less pronounced.
Modelling greenhouse gas emissions in WITCH. The model generates the greenhouse gases reported in Supplementary Table 10, either directly or via exogenous assumptions. Mitigation can happen through technology substitution or storage, direct reduction via marginal abatement cost curves or end of pipe via emission factors. $\mathrm{CO}_{2}$ emission factors are reported in Extended Data Table 3. Emission trajectories are processed through the MAGICC6 climate model, which calculates the climate outcome.

Overview of the MAGICC model. Throughout the analysis we use MAGICC6 for simulating radiative forcing and temperature change. MAGICC is a simple carboncycle climate model originally developed by Wigley and Raper ${ }^{65,93}$. The version 6 is updated to emulate the simulations from large-scale climate models and carboncycle models as represented in the Coupled Model Intercomparison Project 3 $(\mathrm{CMIP} 3)^{40}$ and Coupled Climate Carbon Cycle Model Intercomparison Project $(\mathrm{C} 4 \mathrm{MIP})^{94}$. See ref. 22 for the documentation of the calibration process.

MAGICC has been traditionally used in the IAMs, and most prominently in the development of the RCPs ${ }^{95,96}$. The RCP scenarios in turn were used in large-scale climate models to simulate the future climate in the IPCC Fifth Assessment Report ${ }^{19}$.

Although a simple climate model like MAGICC is by no means a sufficient substitute for the large-scale climate models, its careful calibration to the large-scale climate models and validation exercises ensure the direction and the magnitude of impact is consistent with the current scientific understanding of the climate system. With its flexible structure and fast runtime, MAGICC can be readily integrated into IAMs. Such a smaller computational burden allows IAMs to simulate more future scenarios without needing a supercomputer to run large-scale climate model.

For this study, we have processed all emission trajectories from the IAMs through MAGICC6 to obtain radiative forcing and temperature change. MAGICC allows emulation of a number of climate models. This study uses the default setting used for RCP analysis. The RCP default setting uses median estimates from the climate model inter-comparison exercises $\mathrm{CMIP}^{40}$ and $\mathrm{C}^{4} \mathrm{MIP}^{94}$. For an emulation of carbon cycle model, the C4MIP Bern-CC model ${ }^{97}$ was chosen as it represents the middle of range C4MIP results, and for climate sensitivity $3{ }^{\circ} \mathrm{C}$ is used. The ful documentation of the RCP default setting is available in ref. 96.

The coverage of greenhouses gases and other forcing agents differs widely across five models. The range of forcing agents covered by each model is available in Supplementary Tables 2, 4, 6, 8, and 10 . All models endogenously model $\mathrm{CO}_{2}$. All but WITCH endogenously model $\mathrm{CH}_{4}$ and $\mathrm{N}_{2} \mathrm{O}$. GCAM, MESSAGE, and REMIND endogenously model aerosols and other short-lived species. For the minor forcing agents that the models do not endogenously simulate, we have used exogenous emissions trajectories from the $\mathrm{RCP} 8.5$ scenario ${ }^{96}$ because it best approximates our baseline scenario. Forcing the secondary effect of emissions, such as indirect cloud formation or atmospheric chemistry feedback from non-methane hydrocarbons and other reactive gases, is modelled natively in MAGICC ${ }^{98}$.

31. Riahi, K. et al. Locked into Copenhagen pledges-implications of short-term emission targets for the cost and feasibility of long-term climate goals. Technol. Forecast. Soc. Change (in the press).

32. Nordhaus, W. D. \& Boyer, J. G. Requiem for Kyoto: an economic analysis of the Kyoto Protocol. Energy J. 20, 93-130 (1999).

33. Skone, T. J. Life Cycle Analysis: Natural Gas Combined Cycle (NGCC) Power Plant (National Energy Technology Laboratory, 2010); http://www.netl.doe.gov/ File\%20Library/Research/Energy\%20Analysis/Life\%20Cycle\%20Analysis/ NGCC-LCA-Final-Report---Report---9-30-10---Final---Rev-2.pdf.

34. McCollum, D., Bauer, N., Calvin, K., Kitous, A. \& Riahi, K. Fossil resource and energy security dynamics in conventional and carbon-constrained worlds. Clim. Change 123, 413-426 (2014)

35. Messner, S. \& Strubegger, M. User's Guide for MESSAGE III (International Institute for Applied Systems Analysis, 1995)

36. Luderer, G., Leimbach, M., Bauer, N. \& Kriegler, E. Description of the ReMIND-R model. (Potsdam Institute for Climate Impact Research, 2011); http://www. pik-potsdam.de/research/sustainable-solutions/models/remind/REMIND_ Description.pdf.

37. Integrated Assessment Modeling Consortium IPCC AR5 Scenario Database (IAMC, 2014); https://secure.iiasa.ac.at/web-apps/ene/AR5DB/.

38. Reilly, J. M., Edmonds, J. A., Gardner, R. H. \& Brenkert, A. L. Uncertainty analysis of the IEA/ORAU $\mathrm{CO}_{2}$ emissions model. Energy J. 8, 1-29 (1987).

39. Scott, M. J., Sands, R. D., Edmonds, J., Liebetrau, A. M. \& Engel, D. W. Uncertainty in integrated assessment models: modeling with MiniCAM 1.0. Energy Policy 27, 855-879 (1999).

40. Meehl, G., Covey, C., McAvaney, B., Latif, M. \& Stouffer, R. Overview of the coupled model intercomparison project (CMIP). Bull. Am. Meteorol. Soc. 86, 89-93 (2005).

41. Hertel, T. W. \& Hertel, T. W. Global Trade Analysis: Modeling and Applications (Cambridge Univ. Press, 1999).

42. Hanoch, G. CRESH production functions. Econometrica 39, 695-712 (1971).

43. Harrison, J., Horridge, J., Jerie, M. \& Pearson, K. GEMPACK Manual (2012); http:// www.copsmodels.com/gpmanual.htm.

44. Aguiar, A., McDougall, R. \& Narayanan, B. Global Trade, Assistance and Production: The GTAP 8 Data Base (Center for Global Trade Analysis, Purdue Univ., 2012). 
45. International Energy Agency. $\mathrm{CO}_{2}$ Emissions from Fuel Combustion 2012 (Organisation for Economic Cooperation and Development, 2012).

46. International Energy Agency. Emissions of $\mathrm{CO}_{2}, \mathrm{CH}_{4}, \mathrm{~N}_{2} \mathrm{O}, \mathrm{HFCs}$, PFCs and $\mathrm{SF}_{6}$ (Organisation for Economic Cooperation and Development, 2012).

47. United Nations Framework Convention on Climate Change 2012 Annex I Party GHG Inventory Submissions (UNFCCC, 2012).

48. Environmental Protection Agency. Global Anthropogenic Non- $\mathrm{CO}_{2}$ Greenhouse Gas Emissions: 1990-2030 (US Environmental Protection Agency, 2012).

49. Wigley, T. M. MAGICC/SCENGEN 5.3: User Manual Version 2 (NCAR, 2008).

50. International Energy Agency. $\mathrm{CO}_{2}$ Emissions from Fuel Combustion 1971-2001 (Organisation for Economic Cooperation and Development, 2012).

51. Weyant, J. P., de la Chesnaye, F. C. \& Blanford, G. J. Overview of EMF-21: multigas mitigation and climate policy. Energy J. 27, 1-32 (2006).

52. Edmonds, J. \& Reilly, J. Global energy production and use to the year 2050. Energy 8, 419-432 (1983).

53. Edmonds, J. \& Reilly, J. Global energy and $\mathrm{CO}_{2}$ to the year 2050. Energy J. 4, 21-47 (1983).

54. Edmonds, J. \& Reilly, J. A long-term global energy-economic model of carbon dioxide release from fossil fuel use. Energy Econ. 5, 74-88 (1983).

55. Wise, M. et al. Implications of limiting $\mathrm{CO}_{2}$ concentrations for land use and energy. Science 324, 1183-1186 (2009).

56. Thomson, A. M. et al. RCP4.5: a pathway for stabilization of radiative forcing by 2100. Clim. Change 109, 77-94 (2011).

57. Clarke, J. F. \& Edmonds, J. A. Modelling energy technologies in a competitive market. Energy Econ. 15, 123-129 (1993).

58. Boden, T. A., Marland, G. \& Andres, R. J. Global, Regional, and National Fossil-Fuel $\mathrm{CO}_{2}$ Emissions (Carbon Dioxide Information Analysis Center, Oak Ridge National Laboratory, US Department of Energy, 2009).

59. International Energy Agency. Energy Balances of OECD Countries (Organisation for Economic Cooperation and Development, 2013)

60. International Energy Agency. Energy Balances of Non-OECD Countries (Organisation for Economic Cooperation and Development, 2013)

61. Lamarque, J-F. etal. Historical (1850-2000) gridded anthropogenic and biomass burning emissions of reactive gases and aerosols: methodology and application. Atmos. Chem. Phys. 10, 7017-7039 (2010).

62. Messner, S. \& Schrattenholzer, L. MESSAGE-MACRO: linking an energy supply model with a macroeconomic module and solving it iteratively. Energy $\mathbf{2 5}$ 267-282 (2000).

63. Rao, S. \& Riahi, K. The role of non- $\mathrm{CO}_{2}$ greenhouse gases in climate change mitigation: long-term scenarios for the 21st century. Energy J. 27, 177-200 (2006).

64. Manne, A., Mendelsohn, R. \& Richels, R. MERGE: a model for evaluating regional and global effects of GHG reduction policies. Energy Policy 23, 17-34 (1995).

65. Wigley, T. \& Raper, S. Implications for climate and sea level of revised IPCC emissions scenarios. Nature 357, 293-300 (1992).

66. Arthur, W. B. Competing technologies, increasing returns, and lock-in by historical events. Econ. J. 99, 116-131 (1989).

67. O'Neill, B. C., Riahi, K. \& Keppo, I. Mitigation implications of midcentury targets that preserve long-term climate policy options. Proc. Natl Acad. Sci. USA 107, 1011-1016 (2010)

68. Riahi, K. et al. Energy pathways for sustainable development. In Global Energy Assessment 1203-1306 (Cambridge Univ. Press, 2012).

69. International Energy Agency. World Energy Outlook 2008 (International Energy Agency, 2008).

70. Riahi, K., Rubin, E. S. \& Schrattenholzer, L. Prospects for carbon capture and sequestration technologies assuming their technological learning. Energy 29, $1309-1318$ (2004)

71. Ramage, M. \& Katzer, J. Liquid Transportation Fuels from Coal and Biomass: Technological Status, Costs, and Environmental Impacts (National Academies Press, 2009).

72. Liu, G., Larson, E. D., Williams, R. H., Kreutz, T. G. \& Guo, X. Making Fischer-Tropsch fuels and electricity from coal and biomass: performance and cost analysis. Energy Fuels 25, 415-437 (2011).
73. Liu, G., Williams, R. H., Larson, E. D. \& Kreutz, T. G. Design/economics of low-carbon power generation from natural gas and biomass with synthetic fuels coproduction. Energy Procedia 4, 1989-1996 (2011).

74. Global Energy Assessment GEA Scenario Database (2012); http://www.iiasa.ac.at/ web-apps/ene/geadb/.

75. Rogner, H.-H. An assessment of world hydrocarbon resources. Annu. Rev. Energy Environ. 22, 217-262 (1997).

76. Patwardhan, A. P., Gomez-Echeverri, L., Johansson, T. B. \& Nakićenović, N. Global Energy Assessment: Toward a Sustainable Future (Cambridge Univ. Press, 2012).

77. Weber, C. L. \& Clavin, C. Life cycle carbon footprint of shale gas: review of evidence and implications. Environ. Sci. Technol. 46, 5688-5695 (2012).

78. Rao, S. \& Riahi, K. The role of non- $\mathrm{CO}_{2}$ greenhouse gases in climate change mitigation: long-term scenarios for the 21st century. Energy J. 27, 177-200 (2006).

79. Intergovernmental Panel on Climate Change Guidance and Uncertainty Management in National Greenhouse Gas Inventories 2000 (IPCC Report, 2000).

80. Nordhaus, W. D. \& Yang, Z. A regional dynamic general-equilibrium model of alternative climate-change strategies. Am. Econ. Rev. 86, 741-765 (1996).

81. Leimbach, M., Bauer, N., Baumstark, L., Luken, M. \& Edenhofer, O. Technological change and international trade-insights from REMIND-R. Energy J. 31, 109-136 (2010).

82. Bauer, N., Brecha, R. J. \& Luderer, G. Economics of nuclear power and climate change mitigation policies. Proc. Natl Acad. Sci. USA 109, 16805-16810 (2012).

83. Luderer, G. et al. The economics of decarbonizing the energy system - results and insights from the RECIPE model intercomparison. Clim. Change 114, 9-37 (2012).

84. Edenhofer, O. et al. The economics of low stabilization: model comparison of mitigation strategies and costs. Energy J. 31, 11-48 (2010).

85. Kriegler, E. et al. The role of technology for achieving climate policy objectives: overview of the EMF 27 study on global technology and climate policy strategies. Clim. Change 123, 353-367 (2014).

86. Bauer, N., Edenhofer, O. \& Kypreos, S. Linking energy system and macroeconomic growth models. Comput. Manage. Sci. 5, 95-117 (2008).

87. Schwanitz, V. J., Piontek, F., Bertram, C. \& Luderer, G. Long-term climate policy implications of phasing out fossil fuel subsidies. Energy Policy 67, 882-894 (2014).

88. Klein, D. et al. The value of bioenergy in low stabilization scenarios: an assessment using REMIND-MAgPIE. Clim. Change 123, 705-718 (2013).

89. Strefler, J., Luderer, G., Aboumahboub, T. \& Kriegler, E. Economic impacts of alternative greenhouse gas emission metrics: a model-based assessment. Clim. Change (in the press).

90. International Institute for Applied Systems Analysis Global Biosphere Management Model (IIASA, 2014); http://www.iiasa.ac.at/web/home/research/modelsData/ GLOBIOM/GLOBIOM.en.html.

91. Bosetti, V., Carraro, C., Massetti, E. \& Tavoni, M. International energy R\&D spillovers and the economics of greenhouse gas atmospheric stabilization. Energy Econ. 30, 2912-2929 (2008)

92. Bosetti, V., Carraro, C., Duval, R. \& Tavoni, M. What should we expect from innovation? A model-based assessment of the environmental and mitigation cost implications of climate-related R\&D. Energy Econ. 33, 1313-1320 (2011).

93. Wigley, T. M. \& Raper, S. Thermal expansion of sea water associated with global warming. Nature 330, 127-131 (1987).

94. Friedlingstein, P. et al. Climate-carbon cycle feedback analysis: results from the C4MIP model intercomparison. J. Clim. 19, 3337-3353 (2006).

95. Moss, R. H. et al. The next generation of scenarios for climate change research and assessment. Nature 463, 747-756 (2010).

96. Meinshausen, M. et al. The RCP greenhouse gas concentrations and their extensions from 1765 to 2300. Clim. Change 109, 213-241 (2011).

97. Joos, F. et al. Global warming feedbacks on terrestrial carbon uptake under the Intergovernmental Panel on Climate Change (IPCC) emission scenarios. Glob. Biogeochem. Cycles 15, 891-907 (2001)

98. Wigley, T., Smith, S. J. \& Prather, M. Radiative forcing due to reactive gas emissions J. Clim. 15, 2690-2696 (2002). 
a

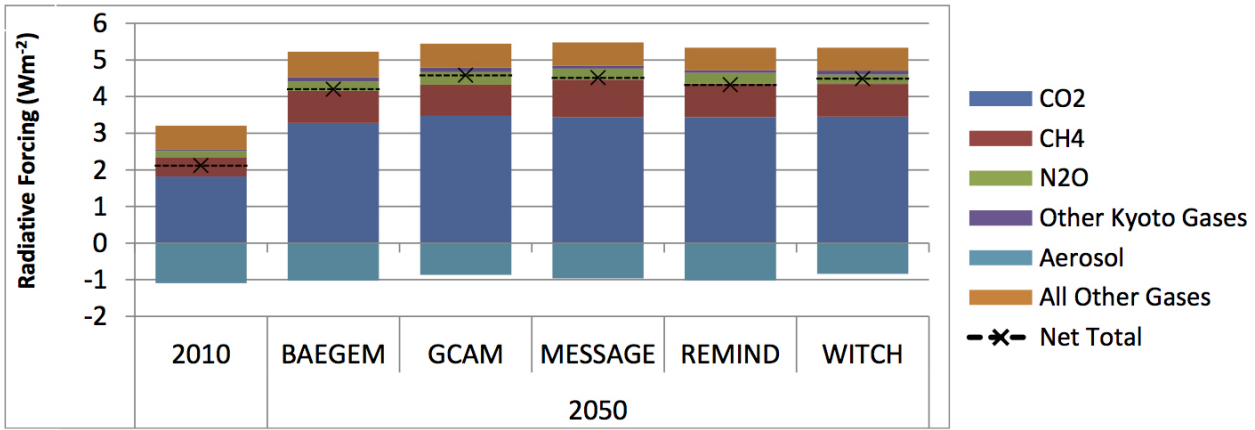

b

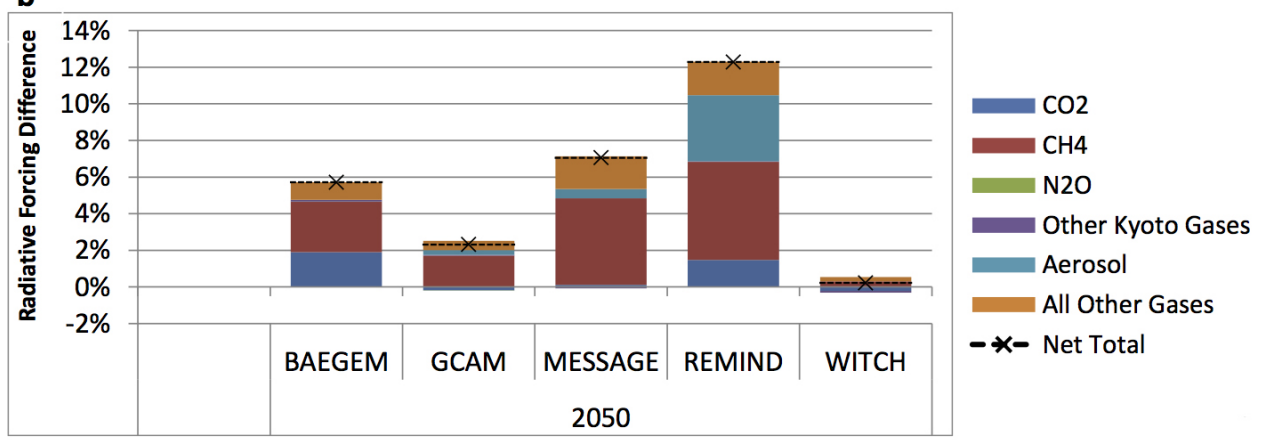

Extended Data Figure 1 Radiative forcing composition for high fugitive methane scenarios. a, Year 2010 and year 2050 composition of radiative forcing for the Conventional Gas scenario with high fugitive methane for five models. b. Year 2050 relative difference in radiative forcing (the Abundant Gas scenario minus the Conventional Gas scenario) all with high fugitive methane assumption for the five models. $1 \%$ difference in forcing for model average is equivalent to $0.044 \mathrm{~W} \mathrm{~m}^{-2}$. 


\section{RESEARCH LETTER}

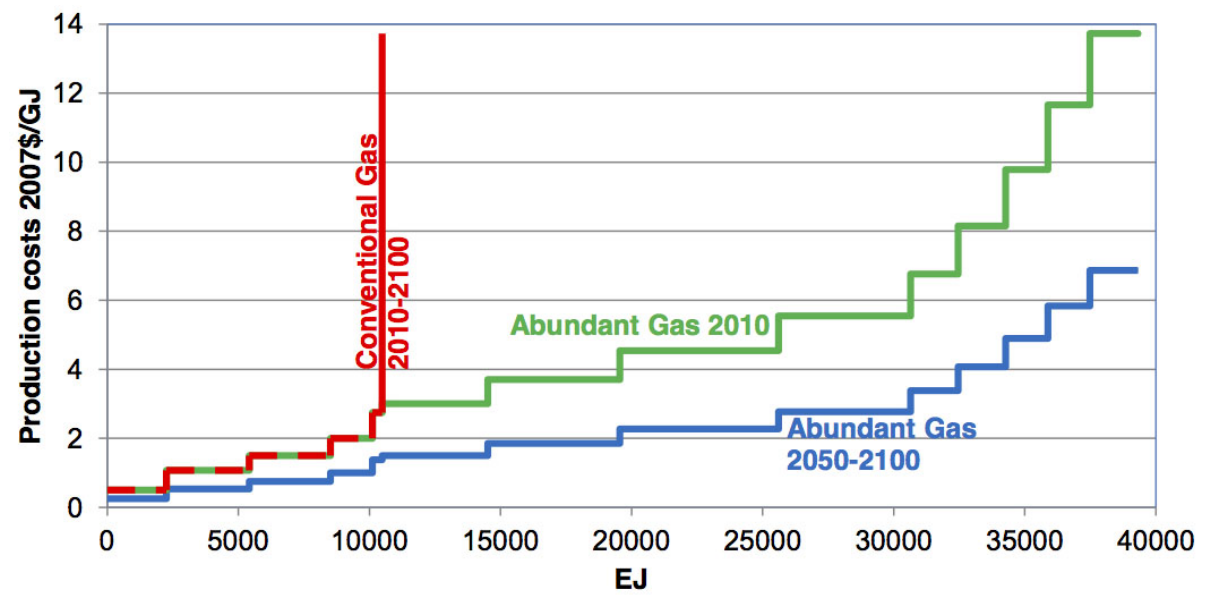

Extended Data Figure $2 \mid$ Global natural gas supply curves. The current natural gas supply curves provided by Global Energy Assessment ${ }^{12}$. Future cost reduction assumptions are documented in the Methods. 
GCAM

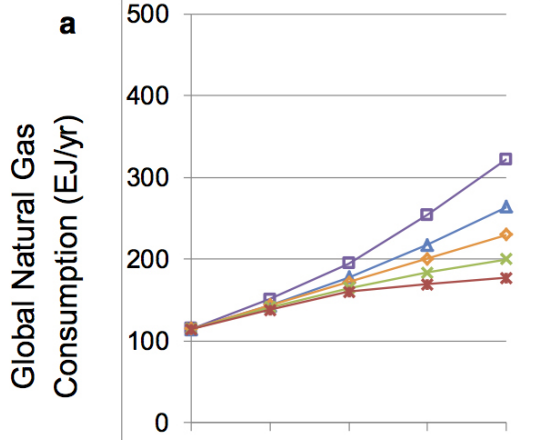

b

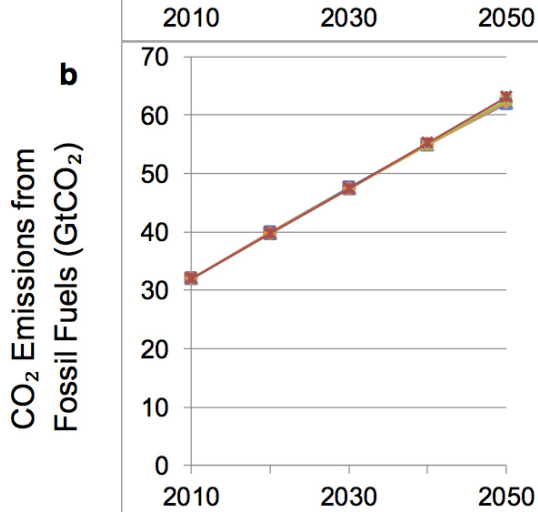

c
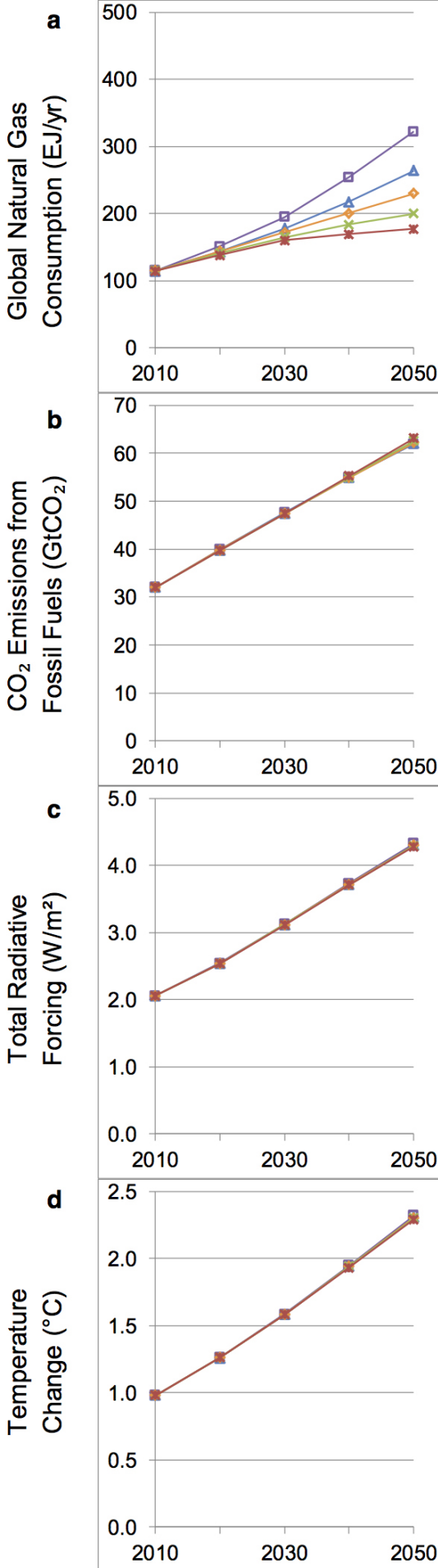

MESSAGE
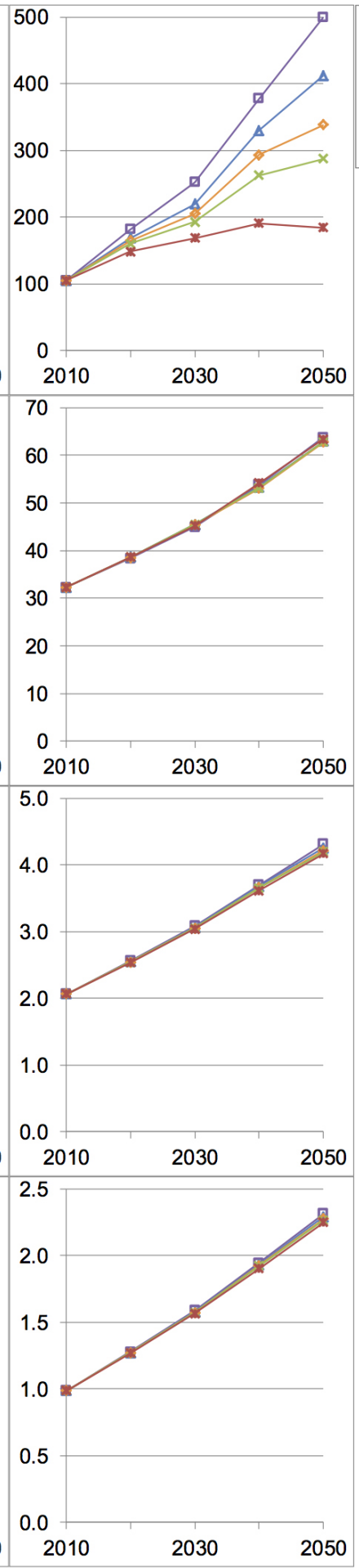

廿-Abundant Gas - 0.75

$\triangle$ Abundant Gas - 0.50

$\rightarrow$ Abundant Gas -0.25

* Abundant Gas -0.00

*-Conventional Gas
Extended Data Figure $3 \mid$ Natural gas supply curve sensitivity analysis. a, Global natural gas consumption. b, $\mathrm{CO}_{2}$ emissions from fossil fuels.

c, Total radiative forcing. d, Global mean surface temperature change (from pre-industrial average 1750-1849). Conventional Gas and Abundant Gas denote the quantity of natural gas supply. The decimal numbers denote the fraction of cost reduction over 2010-2050. 


\section{RESEARCH LETTER}
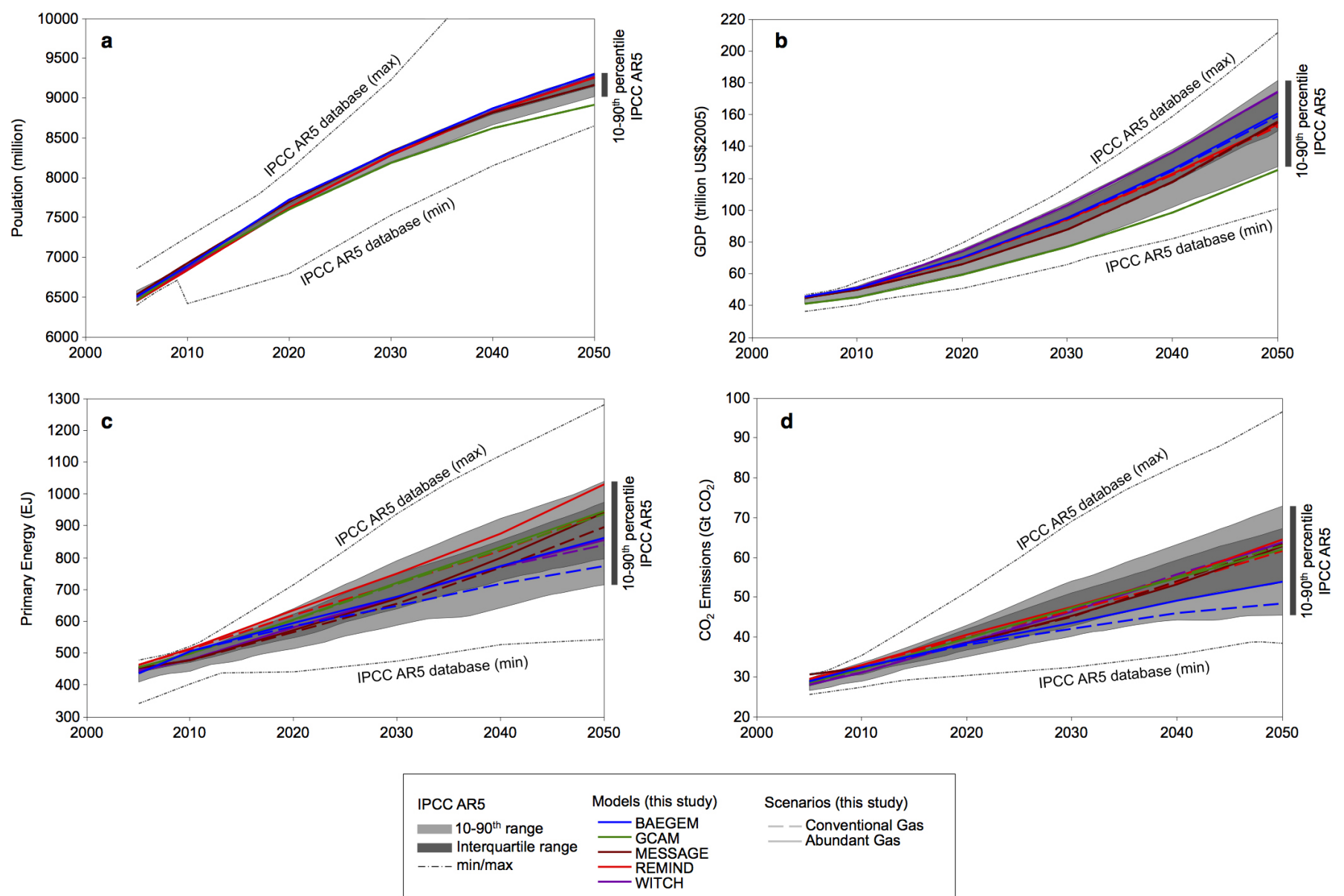

Extended Data Figure $4 \mid$ Uncertainty ranges in principal components of model projections. a, Global population. b, Global GDP. c, Total primary energy consumption. d, Fossil fuel and industrial $\mathrm{CO}_{2}$ emissions. Coloured lines are model reported values from this study. Shaded areas are ranges of projections found in the literature obtained from the IPCC AR5 database ${ }^{37}$. 
Extended Data Table 1 | Cost reduction in low-carbon energy technologies over 2010-2050 in the Abundant Gas scenario

\begin{tabular}{lrrrrrr}
\hline & BAEGEM & GCAM & MESSAGE & REMIND & WITCH & units \\
\hline Solar Photovoltaics & $36 \%$ & $63 \%$ & $58 \%$ & $21 \%$ & $53 \%$ & $\%$ \\
Wind Turbine & $37 \%$ & $21 \%$ & $41 \%$ & $13 \%$ & $40 \%$ & $\%$ \\
Nuclear Powerplant & $29 \%$ & $15 \%$ & $17 \%$ & $0 \%$ & $7 \%$ & $\%$ \\
\hline
\end{tabular}

PV, photovoltaics. 


\section{RESEARCH LETTER}

Extended Data Table 2 | $\mathrm{CO}_{2}$ emissions in 2050 from fossil fuels and industry with standard energy market assumptions and with the coalsubstitution-only assumption

\begin{tabular}{llrrrrrr}
\hline & BAEGEM & GCAM & MESSAGE & REMIND & WITCH & units \\
\hline \multirow{3}{*}{ Standard } & Conventional Gas & 48.5 & 63.1 & 63.4 & 61.7 & 63.8 & $\mathrm{GtCO}_{2}$ \\
& Abundant Gas & 54.0 & 62.1 & 62.9 & 64.6 & 63.9 & $\mathrm{GtCO}_{2}$ \\
& Difference & 5.5 & -1.1 & -0.5 & 2.9 & 0.0 & $\mathrm{GtCO}_{2}$ \\
\hline \multirow{2}{*}{$\begin{array}{l}\text { Coal } \\
\text { Substitution }\end{array}$ Only } & Conventional Gas & 48.5 & 63.1 & 63.4 & 61.7 & 63.8 & $\mathrm{GtCO}_{2}$ \\
& Abundant Gas & 51.9 & 60.4 & 59.7 & 60.4 & 63.8 & $\mathrm{GtCO}_{2}$ \\
& Difference & 3.3 & -2.8 & -3.8 & -1.3 & -0.0 & $\mathrm{GtCO}_{2}$ \\
\hline
\end{tabular}




\section{LETTER RESEARCH}

Extended Data Table 3 | 2050 emission factors for fossil fuels in each model

\begin{tabular}{rlrrrrrr}
\hline & & BAEGEM & GCAM & MESSAGE & REMIND & WITCH & units \\
\hline \multirow{2}{*}{$\mathrm{CO}_{2}$} & Coal & 101 & 100 & $95-101$ & 96 & 90 & $\mathrm{kgCO}_{2} / \mathrm{GJ}$ \\
& Oil & 79 & 72 & 73 & 68 & 70 & $\mathrm{kgCO}_{2} / \mathrm{GJ}$ \\
& Gas & 59 & 52 & 56 & 56 & 55 & $\mathrm{kgCO}_{2} / \mathrm{GJ}$ \\
\hline \multirow{2}{*}{$\mathrm{CH}_{4}$} & Coal & 0.21 & 0.14 & 0.39 & 0.12 & $\mathrm{~N} / \mathrm{A}$ & $\mathrm{kgCH}_{4} / \mathrm{GJ}$ \\
& Oil & 0.11 & 0.06 & 0.06 & 0.06 & $\mathrm{~N} / \mathrm{A}$ & $\mathrm{kgCH}_{4} / \mathrm{GJ}$ \\
& Gas & 0.32 & 0.35 & 0.31 & 0.52 & $\mathrm{~N} / \mathrm{A}$ & $\mathrm{kgCH}_{4} / \mathrm{GJ}$ \\
\hline
\end{tabular}

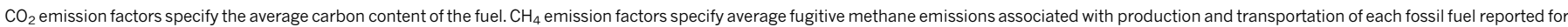
the Abundant Gas scenario. 


\section{RESEARCH LETTER}

Extended Data Table 4 | 2050 anthropogenic radiative forcing with standard fugitive methane emission assumptions and with high fugitive methane emission assumptions

\begin{tabular}{|c|c|c|c|c|c|c|c|}
\hline & & BAEGEM & GCAM & MESSAGE & REMIND & WITCH & units \\
\hline \multirow{3}{*}{ Standard } & Conventional Gas & 3.97 & 4.46 & 4.25 & 4.16 & 4.38 & $\mathrm{~W} \mathrm{m^{-2 }}$ \\
\hline & Abundant Gas & 4.07 & 4.49 & 4.37 & 4.46 & 4.37 & $\mathrm{~W} \mathrm{m^{-2 }}$ \\
\hline & Difference & 0.10 & 0.02 & 0.12 & 0.31 & -0.01 & $\mathrm{~W} \mathrm{m^{-2 }}$ \\
\hline \multirow{3}{*}{$\begin{array}{l}\text { High } \\
\text { Fugitive } \\
\text { Methane }\end{array}$} & Conventional Gas & 4.20 & 4.58 & 4.51 & 4.32 & 4.49 & $\mathrm{~W} \mathrm{m^{-2 }}$ \\
\hline & Abundant Gas & 4.44 & 4.69 & 4.83 & 4.85 & 4.50 & $\mathrm{~W} \mathrm{m^{-2 }}$ \\
\hline & Difference & 0.24 & 0.11 & 0.32 & 0.53 & 0.01 & $\mathrm{~W} \mathrm{\textrm {m } ^ { - 2 }}$ \\
\hline
\end{tabular}

